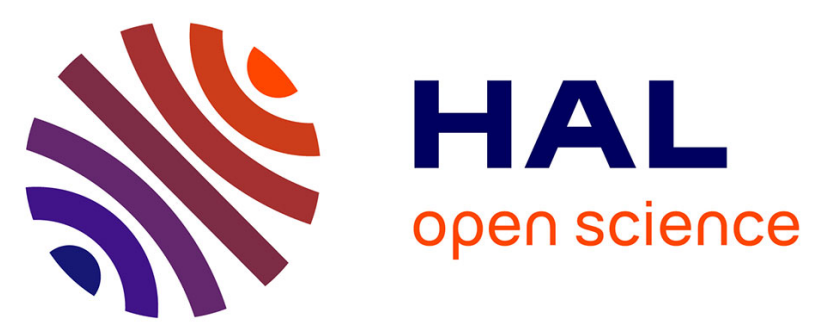

\title{
Density Functional Theory Study of the Spontaneous Formation of Covalent Bonds at the Silver/Silica Interface in Silver Nanoparticles Embedded in $\mathrm{SiO} 2$ : Implications for Ag + Release
}

Hilal Balout, Nathalie Tarrat, Joël Puibasset, Simona Ispas, Caroline Bonafos, Magali Benoit

\section{To cite this version:}

Hilal Balout, Nathalie Tarrat, Joël Puibasset, Simona Ispas, Caroline Bonafos, et al.. Density Functional Theory Study of the Spontaneous Formation of Covalent Bonds at the Silver/Silica Interface in Silver Nanoparticles Embedded in $\mathrm{SiO} 2$ : Implications for $\mathrm{Ag}+$ Release. ACS Applied Nano Materials, 2019, 2 (8), pp.5179-5189. 10.1021/acsanm.9b01049 . hal-02381450

\author{
HAL Id: hal-02381450 \\ https://hal.science/hal-02381450
}

Submitted on 26 Nov 2019

HAL is a multi-disciplinary open access archive for the deposit and dissemination of scientific research documents, whether they are published or not. The documents may come from teaching and research institutions in France or abroad, or from public or private research centers.
L'archive ouverte pluridisciplinaire HAL, est destinée au dépôt et à la diffusion de documents scientifiques de niveau recherche, publiés ou non, émanant des établissements d'enseignement et de recherche français ou étrangers, des laboratoires publics ou privés. 


\title{
Density Functional Theory Study of the
}

\section{Spontaneous Formation of Covalent Bonds at}

\section{the Silver-Silica Interface in Ag Nanoparticles}

\section{Embedded in $\mathrm{SiO}_{2}$ : Implications for $\mathrm{Ag}^{+}$release}

\author{
Hilal Balout, ${ }^{\dagger}$ Nathalie Tarrat, ${ }^{\dagger}$ Joël Puibasset, ${ }^{\ddagger}$ Simona Ispas, ${ }^{\circledR}$ Caroline
} Bonafos, $^{\dagger}$ and Magali Benoit ${ }^{*, \dagger}$

†CEMES-CNRS and Université de Toulouse, 29 rue Jeanne Marvig, 31055 Toulouse Cedex 4, France

$\ddagger I C M N-C N R S$ - Université d'Orléans, $1 b$ rue de la Férollerie, CS 40059, 45071 Orléans Cedex 2, France

\Laboratoire Charles Coulomb (L2C), Univ. Montpellier, CNRS, F-34095 Montpellier, France

E-mail: mbenoit@cemes.fr

Phone: $+33(5) 62257970$

\begin{abstract}
Silver nanoparticles (AgNPs) are widely used in health-care sector and industrial applications because of their outstanding antibacterial activity. This bactericidal effect is mainly attributed to the release of $\mathrm{Ag}^{+}$ions in the aqueous medium, the first step of which is the dissolution of the AgNP via the oxidation of its surface by $\mathrm{O}_{2}$. With the aim of designing more durable and less toxic anti-bacterial devices, it is desirable to finetune the rate of $\mathrm{Ag}^{+}$release into the surrounding environment. This can be achieved
\end{abstract}


by choosing an adequate coating of the AgNPs, e.g. by embedding the nanoparticles in a silica matrix. In previous works [A. Pugliara et al., Sci Total Environ. (2016) 565, 863], we have shown that the toxic effect on algae photosynthesis of small AgNPs (size $<20 \mathrm{~nm}$ ) embedded in silica layers is preserved, provided that the distance between the AgNPs and the silica free surface is below $\approx 6-7 \mathrm{~nm}$. A better control of the $\mathrm{Ag}^{+}$release rate in these systems requires a better understanding of the elementary mechanisms at play concerning both the detachment of the Ag ions from the AgNPs and their diffusion through $\mathrm{SiO}_{2}$. A first step in this direction consists in characterizing the interface between the AgNPs surface and the silica matrix. In this context, periodic DFT calculations have been performed on model systems representing the interfaces between amorphous silica and the three crystalline facets of $\operatorname{AgNPs}$, i.e. $\operatorname{Ag}(111)$, $\mathrm{Ag}(110)$ and $\mathrm{Ag}(100)$. Spontaneous breaking of Si-O bonds and formation of two O-Ag and one $\mathrm{Si}-\mathrm{Ag}$ bonds are observed in $50 \%$ of the investigated interfaces, corresponding to 1.8 bonds $/ \mathrm{nm}^{2}$ on average. The covalent nature of the bonds between $\mathrm{Ag}$ and $\mathrm{O}$ and between $\mathrm{Ag}$ and $\mathrm{Si}$ is highlighted by the analysis of the electronic structure of the interfaces.

\section{Introduction}

Silver as a disinfectant has been used since antiquity and, in the form of salt or of nanosystems, has shown its effectiveness as an anti-bacterial agent, initially for the treatment of wounds since the 1950 's. ${ }^{1}$ In the form of nanoparticles, the toxicity of silver can come either from the action of the nanoparticle as such, ${ }^{2,3}$ or from the action of $\mathrm{Ag}^{+}$ions released by the nanoparticle, ${ }^{4}$ the latter constituting a reservoir of these ions. In this case, the $\mathrm{Ag}^{+}$ions release is due to the dissolution of the nanoparticle by oxidation of its surface. ${ }^{5-9}$ Several molecules have been identified as binding to the $\mathrm{Ag}^{+}$ion, known to interact non specifically to a wide variety of organic moiety, leading to the $\mathrm{Ag}^{+}$toxicity against bacteria, ${ }^{10}$ algae ${ }^{11}$ biofilms, ${ }^{12}$ aquatic species, ${ }^{13}$ and human cells. ${ }^{14}$ 
Experimental results have shown that the release of $\mathrm{Ag}^{+}$ions by $\mathrm{AgNPs}$ depends on many factors that can accelerate it, slow it down or even stop it : surface coating, functionalization, $\mathrm{pH}$, temperature, dissolved oxygen concentration, NP size or the presence of other ions. ${ }^{8,9,15,16}$ For example, it has been shown that the $\mathrm{Ag}^{+}$release is very fast when $\mathrm{AgNPs}$ are immersed in a liquid environment (water or physiological environment) but that this release rate decreases significantly or even stops after a certain time. ${ }^{6}$ This release cessation is attributed to the presence of an oxide layer on the surface of the AgNPs that would inhibit the release. ${ }^{5,6,8}$ In addition, it has been shown that the $\mathrm{Ag}^{+}$release also depends strongly on the type of ligands that are used to stabilize the AgNPs. ${ }^{9,15}$

These limiting factors can be used to fine-tune the rate of $\mathrm{Ag}^{+}$release into the surrounding environment, so as to obtain more durable and less toxic anti-bacterial devices. By controlling the release mechanism, one could imagine not only to tune the release rate, but also to control the total dose of released $\mathrm{Ag}^{+}$ions. This latter can be achieved by using different types of coating. Indeed, an appropriate coverage should be able to slow down the release without stopping it completely, which would allow the device to last longer. ${ }^{9,15}$ For instance, it has been shown that $\mathrm{Ag}^{+}$release is systematically slowed down by the binding of ligands at the AgNP surface, such as thiol and citrate. ${ }^{15}$ On the contrary, release can be strongly enhanced by the presence of $\mathrm{H}_{2} \mathrm{O}_{2}$ as an oxidator. ${ }^{16,17}$ Another way of controlling the $\mathrm{Ag}^{+}$release consists in coating the AgNPs by a protective dielectric layer. Recently, several authors have attempted this type of coating, ${ }^{18}$ either by manufacturing $\mathrm{Ag} @ \mathrm{SiO}_{2}$ core-shell nanoparticles by flame aerosol ${ }^{19,20}$ or chemical routes, ${ }^{21}$ by heat treating $\mathrm{SiO}_{2}$-Ag composite powders ${ }^{22}$ by dispersing AgNPs in a silica matrix by electrolysis of a pure Ag electrode, ${ }^{23}$ or by synthesizing AgNPs embedded in a silica matrix by ion beam implantation or combining sputtering and plasma polymerization. ${ }^{24}$ Results obtained on the performance of the silica layer regarding the control of the $\mathrm{Ag}^{+}$release show that it strongly depends on the nature of the silica matrix (composition, structure, defects ...). Besides, in the case of dense silica layers, it has been shown that beyond a given thickness of silica between the particle and the medium, 
the $\mathrm{Ag}^{+}$release decreases or even stops. ${ }^{19,24}$ These studies have reported different values for the "threshold" thickness at which there is no further release. Indeed, in the case of dry-coated $\mathrm{Ag} @ \mathrm{SiO}_{2}$ nanoparticles, the absence of release seems to occur from a thickness of 3-4 $\mathrm{nm}^{19}$ whereas in the case of AgNPs embedded in a silica matrix, it occurs for a distance of 6-7 nm between the AgNP and the silica external surface. ${ }^{24}$ Fig. 1(a) is a typical bright field cross-sectional transmission electron microscopy (TEM) image of AgNPs formed by low energy ion implantation in thermal silica, such as the ones studied in Ref. ${ }^{24}$ The AgNPs are small, with size less than $10 \mathrm{~nm}$ and located at nanometer distance from the silica surface. Some of them are twinned ${ }^{25}$ and all are faceted (Fig. 1(b)), as it will be commented later.

These results raise fundamental questions that are important to address if one wants to be able to adjust more finely the release of $\mathrm{Ag}^{+}$ions by this type of coating. First of all, how does the silica nature (hydrated, mesoporous, thermal...) influence the $\mathrm{Ag}^{+}$release? What is the nature of the interface between silica and the AgNPs? What is the detachment mechanism of the Ag atoms from the nanoparticle when they are protected by a silica shell? Why does the release no longer take place when the silica layer reaches a specific thickness?

To answer these questions, it is first necessary to characterize the nature of the interface between amorphous silica and the AgNPs. Obviously this interface strongly depends on the shape and size of the AgNPs, on the way the silica coating was experimentally realized and, consequently, on the nature of the silica layer. In the present paper, we have chosen to study the simplest case of an interface between the crystalline facets of the AgNP and a dense and dry silica layer. This is expected to correspond to our previous experimental study on AgNPs embedded in a silica matrix. ${ }^{24}$

Theoretically, the interface between amorphous silica and a metal has already been investigated, especially in the case of $\mathrm{Pt}$ where bonds are formed spontaneously at the $\mathrm{SiO}_{2} / \mathrm{Pt}$ interface. $^{26,27}$ At the surface of amorphous silica, Si-O dangling bonds are passivated by silanol groups $(\mathrm{Si}-\mathrm{O}-\mathrm{H})$. In some cases, these $\mathrm{Si}-\mathrm{O}-\mathrm{H}$ groups are replaced by Si-O-M, M being the metal considered. ${ }^{28}$ The reactivity of the silica surface towards metals depends 
strongly on the type of metal and in particular on the strength of Si-M bonds and the ability of the metal to make silicides. In the case of $\mathrm{AgNPs}$ implanted in a silica matrix, even if water enters the silica just after the implantation process, it is most likely that the annealing carried out after implantation will lead to the total or partial evacuation of this water. ${ }^{29}$ Fig. 1(a) presents the scheme of the synthesis of AgNPs by Ultra-Low Energy Ion Implantation of $\mathrm{Ag}^{+}$in thermal silica on top of a Si substrate. The low energy range allows the formation of a $2 \mathrm{D}$ array of AgNPs at nanometer distance from the $\mathrm{SiO}_{2}$ free surface (Fig.1(b)) . In our previous experiments, ${ }^{24}$ the samples were further annealed under $\mathrm{N}_{2}$ atmosphere at a temperature of $500 \mathrm{C}$ for damage recovering and it has been shown that thermal treatment of silica surface leads to a partial dehydroxilation of the surface for temperatures above 400 ${ }^{\circ} \mathrm{C}$ and to a complete one for temperatures as high as $1000{ }^{\circ} \mathrm{C}^{30,31}+\mathrm{REF}$. In addition, the effect of temperature during the annealing should lead to a higher reactivity of the silica surface towards the metallic nanoparticles. It is therefore most likely that direct chemical bonding between the AgNP surfaces and the silica matrix could exist.

In this context, we have undertaken Density Functional Theory (DFT) studies of the interfaces between amorphous silica and the main facets of AgNPs. These latter were chosen based on the AgNP morphology determined using High Resolution Transmission Electron Microscopy (HRTEM). Fig. 1(c) shows a HRTEM image of an individual AgNP of $6 \mathrm{~nm}$ diameter projected along the $<110>$ orientation, representative of the AgNP population. The measured interplanar distances and angles are characteristics of the face centred cubic (FCC) Ag structure and the NP shows 4 (111) and 2 (100) facets, characteristics of the truncated-octahedron equilibrium shape (Fig. 1(d)). ${ }^{32}$ Small (110) facets could also be present in truncated octahedron morphology but are difficult to assess experimentally in HRTEM images for such small sizes. Based on these observations, we decided to consider the three $\operatorname{Ag}(111), \operatorname{Ag}(110)$ and $\operatorname{Ag}(100)$ facets for the silver/silica interface modeling. Note that in Ref., ${ }^{33}$ the comparison between calculated vibration density of states (VDOS) and the one extracted from plasmon resonance Raman scattering ${ }^{34}$ shows best agreement for the 
icosahedral morphology. Nevertheless, this theoretical model was based on an ideal isolated structure in vacuum, far from the experimental assembly of matrix embedded and sizedistributed AgNPs. In particular, it does not take into account effects of surface disorder, binding heterogeneities and very local strain, which may have an impact on the VDOS. Even if large icosahedral AgNPs can be produced by deposition techniques as gas aggregation sources, ${ }^{35}$ their existence is ascribed to the formation of metastable structures, grown under conditions dominated by kinetic factors.
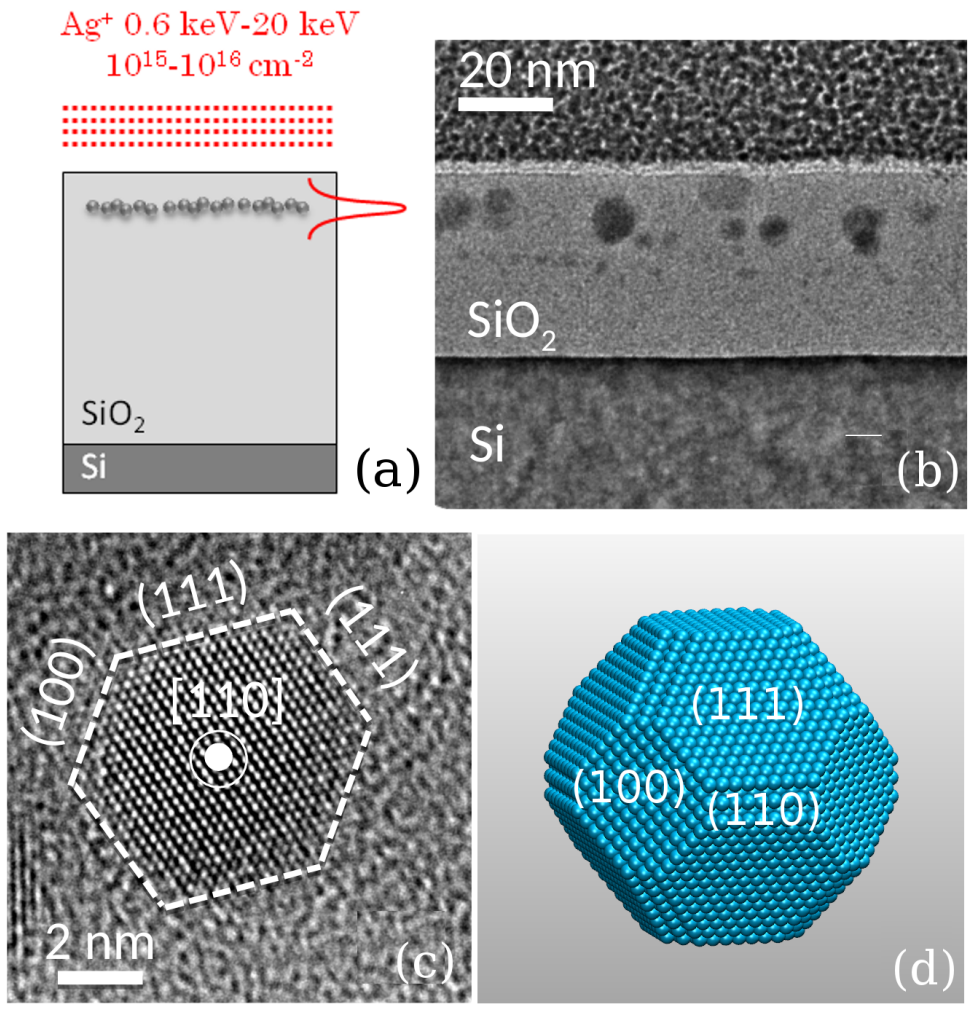

Figure 1: (a) Scheme of the synthesis of AgNPs by Ultra-Low Energy Ion Implantation of $\mathrm{Ag}^{+}$in thermal silica on top of a Si substrate; (b) typical bright field cross-sectional TEM image of AgNPs formed by low energy ion implantation in thermal silica as the ones studied in reference; ${ }^{24}$ (c) HRTEM image of an individual $\mathrm{NC}$ of $6 \mathrm{~nm}$ diameter projected along the $<110>$ orientation, representative of the NC population; (d) truncated-octahedron morphology as obtained from the Wulff construction using the PBE-D3 surface energies (see Tab. ??).

In this paper, we first present how the interfaces between the different AgNP facets and amorphous silica were built, then we focus on describing their structure in detail. We show 
that interface reconstructions leading to the breaking of $\mathrm{Si}-\mathrm{O}$ bonds and the formation of Ag-O and Ag-Si bonds occur spontaneously at 0K, regardless of the type of silver facet facing silica. These reconstructions are then analyzed in terms of their electronic properties. A discussion is then conducted, leading to the hypothesis that the spontaneous formation of interface bonds could initiate silver ion detachment when nanoparticles are implanted in a silica matrix.

\section{Computational details}

The atomistic properties of the $\mathrm{Ag} / \mathrm{SiO}_{2}$ interface have been investigated by means of electronic structure calculations in the DFT framework. This choice was dictated by the desire to make no preliminary assumption (or hypothesis) as to the type of interaction that could exist between the Ag surfaces and the amorphous silica. We have also added dispersion forces, which are not taken into account in standard DFT. Calculations were carried out

with the VASP code under periodic boundary conditions using PAW pseudopotentials. ${ }^{36,37}$ The exchange and correlation functionals together with some of the available dispersion interactions have been first tested on a silica crystalline polymorph, the cristobalite, and on the Ag bulk and surfaces. Results of these calculations were used to choose the functional for the $\mathrm{Ag} / \mathrm{SiO}_{2}$ interface simulations.

\section{$\mathrm{SiO}_{2}$}

The following exchange and correlation functionals and dispersion interactions have been tested on the structural properties of bulk $\alpha$-cristobalite, a silica polymorph which density is close to the amorphous silica density $\left(2.2\right.$ g.cm $\left.{ }^{-3}\right)$ : The GGA functionals PBE ${ }^{38}$ and PBEsol, ${ }^{39}$ the empirically dispersion-corrected functionals PBE-D2, ${ }^{40}$ PBE-D3 ${ }^{41}$ and PBEsol-D2 and the non-local dispersion-corrected optB86b functional. ${ }^{42}$ The results are presented in Tab. 1 for an orthogonal cell of 12 atoms. For these calculations, a cutoff 
energy of $750 \mathrm{eV}$ and a Monkhorst-Pack k-points grid of 4x4x2 were necessary to converge the total energy within an accuracy of $1 \mathrm{meV} /$ atom.

Table 1: Structural characteristics of alpha-cristobalite (lattice parameter and Si-O bond distances in $\AA$ and Si-O-Si angles in degrees) and of fcc Ag bulk (lattice parameter in $\AA$ ) and surface (surface energies $\gamma$ in $\mathrm{J} / \mathrm{m}^{2}$ and first interlayer distance variations with respect to the bulk ones $\Delta \mathrm{d}_{12}$ in $\%$ ), as obtained using different exchange and correlation functionals and dispersion forces.

\begin{tabular}{|l|ccccccc|}
\hline \hline $\mathrm{SiO}_{2}$ & PBE & PBE-D2 & PBE-D3 & PBEsol & PBEsol-D2 & optB86b & Exp. \\
\hline $\mathrm{a}$ & 5.109 & 5.004 & 4.993 & 5.070 & 4.890 & 4.930 & $4.957^{43}$ \\
$\mathrm{c}$ & 7.155 & 6.951 & 6.915 & 7.081 & 6.717 & 6.801 & $6.972^{44}$ \\
& & & & & & & $6.890^{43}$ \\
$\mathrm{a} / \mathrm{c}$ & 0.714 & 0.720 & 0.722 & 0.716 & 0.728 & 0.725 & $0.712^{43}$ \\
& & & & & & & $0.718^{44}$ \\
$\mathrm{~d}_{\text {SiO }}$ & 1.624 & 1.627 & 1.625 & 1.619 & 1.627 & 1.626 & $1.602 / 1.617^{43}$ \\
& & & & & & & $1.602 / 1.603^{44}$ \\
$\widehat{S i O S} i$ & 151.0 & 143.9 & 143.2 & 149.4 & 138.0 & 139.7 & $144.7^{43}$ \\
& & & & & & & $146.5^{44}$ \\
\hline \hline $\mathrm{Ag}$ & PBE & PBE-D2 & PBE-D3 & PBEsol & PBEsol-D2 & optB86b & Exp. \\
\hline $\mathrm{a}$ & 4.164 & 4.154 & 4.093 & 4.072 & 4.032 & 4.108 & $4.085^{45}$ \\
$\gamma_{100}$ & 0.814 & - & 1.378 & - & - & 1.164 & $1.3^{46}$ \\
$\Delta \mathrm{d}_{12}^{100}$ & -2.05 & - & +0.70 & - & - & +1.49 & $0.0 \pm 1.5^{46}$ \\
$\gamma_{110}$ & 0.876 & - & 1.458 & - & - & 1.230 & - \\
$\Delta \mathrm{d}_{12}^{110}$ & 8.50 & - & -4.54 & - & - & -7.11 & $-7.8 \pm 2.5^{47}$ \\
$\gamma_{111}$ & 0.741 & - & 1.345 & - & - & 1.088 & $1.20 / 1.25^{46}$ \\
$\Delta \mathrm{d}_{12}^{111}$ & -0.36 & - & +1.00 & - & - & -0.25 & $0.0 /-2.5^{46,48}$ \\
\hline \hline
\end{tabular}

Taking into account the results reported in Tab. 1, we conclude that the dispersioncorrected PBE-D3 functional ${ }^{41}$ is the one reproducing the best the lattice parameters and the bond lengths and angles of cristobalite. It is interesting to note, however, that none of these functionals are able to describe properly the Si-O bond length with a great accuracy (between $+1.1 \%$ and $+1.6 \%$ with respect to $1.602 \AA$ ). This is in line with a recent study on the effect of dispersion interactions on the structural and energetic properties of silica polymorphs. ${ }^{49}$ 


\section{Ag bulk and surface}

The same exchange and correlation energy functionals were also tested on bulk Ag lattice parameter for the fcc cell containing 4 atoms and the results are presented in Tab. 1. For these calculations, the cutoff energy was set to $450 \mathrm{eV}$, the Monkhorst-Pack k-points grid to $18 \times 18 \times 18$ and we used a Methfessel-Paxton electron occupation function with a smearing parameter of $0.1 \mathrm{eV}$.

Three functionals reproduce the Ag experimental parameter with a great accuracy (less than 1\%): PBE-D3 (+0.20\%), PBEsol $(-0.32 \%)$ and optB86b (+0.56 \%). Since we wish to work with the best functionals for both systems, $\mathrm{SiO}_{2}$ and $\mathrm{Ag}$, we selected the PBE-D3 and optB86b functionals to test the surface properties of $\mathrm{Ag}$, namely the surface energy and the first interlayer distance variation with respect to the bulk. The calculated values using these 2 functionals as well as the PBE one for comparison are given in Tab. 1.

The PBE-D3 functional gives calculated surface energies close to the experimental values for the (100) and (111) surfaces. The surface energies have been obtained using slabs of $M$ layers perpendicular to the investigated $\mathrm{Ag}(\mathrm{hkl})$ crystalline facet. The corresponding surface energy $\gamma_{h k l}$ is then computed using:

$$
E_{s l a b}(h k l)=N_{A g} E_{a t}+2 \gamma_{h k l}
$$

where $E_{\text {slab }}(h k l)$ is the total energy of a $\mathrm{Ag}(\mathrm{hkl})$ slab of a $M$ layers, $N_{A g}$ is the number of $\mathrm{Ag}$ atoms in the slab, $E_{a t}$ is the atomic energy of a $\mathrm{Ag}$ atom in the bulk and $\gamma_{h k l}$ is the surface energy. The surface energy is obtained by increasing the number of layers until convergence is reached within an accuracy of $\pm 2 \mathrm{~mJ} / \mathrm{m}^{2}$ ( $\mathrm{M}=20$ for (100) and (110) and $\mathrm{M}=21$ for (111)). For all functionals, the surface energies are ordered as $\gamma_{111}<\gamma_{100}<\gamma_{110}$ which is consistent with the experimental hierarchy. Note, however, that their values strongly differ depending on whether the dispersion corrections are included or not. Regarding the variation of the interlayer distances due to the presence of the surface, one can notice that for the (100) 
surface, all the values lie within the experimental range except for the PBE functional. For the (110) surface, there is a strong contraction of the first interlayer distance which is well-reproduced by all functionals. However, the calculated first interlayer distance for the (111) surface is not in agreement with the experimental contraction whatever the functional. This discrepancy is certainly due to the fact that we do not take into account the surface reconstruction.

Given the results obtained for both the $\alpha$-cristobalite and the Ag bulk and surfaces properties, we decided to work with the PBE-D3 functional for the investigation of the $\mathrm{Ag} / \mathrm{SiO}_{2}$ interface properties.

\section{$\mathrm{Ag} / \mathrm{SiO}_{2}$ interfaces}

Given the computational cost of this type of calculations, it is not possible to model a nanoparticle of several nanometers surrounded by a silica matrix. We have therefore chosen to model the interfaces between the most energetically favorable facets of AgNPs and silica by means of periodic calculations. Three types of interfaces have been considered: $\mathrm{Ag}(111) / \mathrm{SiO}_{2}, \mathrm{Ag}(110) / \mathrm{SiO}_{2}$ and $\mathrm{Ag}(100) / \mathrm{SiO}_{2}$.

To model these interfaces, the systems are composed of two slabs of similar thickness: one made of $N$ layers of $\mathrm{Ag}$ and the other made of pre-equilibrated amorphous silica, leading to two $\mathrm{Ag} / \mathrm{SiO}_{2}$ interfaces per simulation cell. The size of this latter is large enough to model the structural disorder of amorphous silica and is a multiple of the Ag unit cell in the $\mathrm{x}$ and y directions, for each crystalline facet. The systems were then made of $58 \mathrm{SiO}_{2}$ and $150 \mathrm{Ag}$ atoms (5 layers) for $\mathrm{Ag}(111) / \mathrm{SiO}_{2}$, of $38 \mathrm{SiO}_{2}$ and $96 \mathrm{Ag}$ atoms (8 layers) for $\mathrm{Ag}(110) / \mathrm{SiO}_{2}$ and of $40 \mathrm{SiO}_{2}$ and $108 \mathrm{Ag}$ atoms (6 layers) for $\mathrm{Ag}(100) / \mathrm{SiO}_{2}$ (see Fig. 2). The number of Ag layers have been chosen in order to satisfy the compromise between accuracy and computational cost. With these number of layers, the Ag slab thicknesses are of the same order than that of the $\mathrm{SiO}_{2}$ slabs, and the deviation of the interlayer distance from the bulk 
is as large as $-2.7 \%$ for $\mathrm{Ag}(100), \pm 4.7 \%$ for $\mathrm{Ag}(110)$ and $-0.6 \%$ for $\mathrm{Ag}(111)$ in the middle of the slabs. Note that the high value obtained for $\mathrm{Ag}(110)$ is consistent with the large contraction of the first interlayer (Tab. 1).
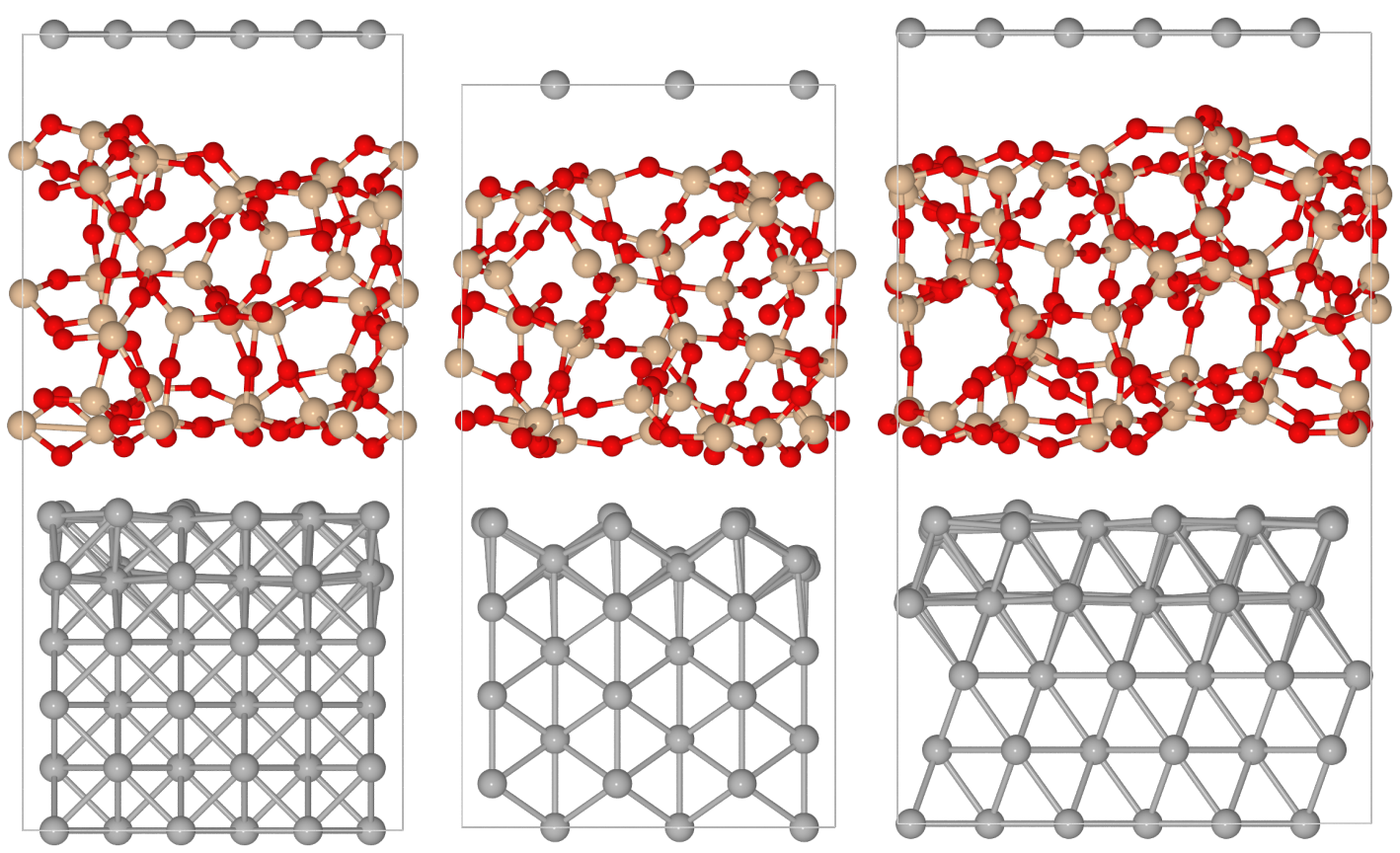

Figure 2: Initial models of Sample 1 of $\mathrm{Ag}(100) / \mathrm{SiO}_{2}$ (left), Sample 1 of the $\mathrm{Ag}(110) / \mathrm{SiO}_{2}$ (middle) and Sample 1 of the $\mathrm{Ag}(111) / \mathrm{SiO}_{2}$ (right).

The pre-equilibrated amorphous silica thin films were prepared using Monte Carlo simulations with the m-TTAM potential which reproduces well the structure of silica polymorphs. ${ }^{50,51}$ A sample of bulk silica was equilibrated in the liquid state (4000 K) for $10^{6} \mathrm{MC}$ steps per atom in a box of lateral dimensions $\mathrm{Lx}$ and Ly corresponding to that of the $\mathrm{Ag}$ film, and $\mathrm{Lz}=12.24 \AA$, with periodic boundary conditions (PBC). The system was then cooled down by applying temperature drops and subsequent equilibrations at $2000 \mathrm{~K}, 1000$ $\mathrm{K}, 600 \mathrm{~K}$ and $300 \mathrm{~K}$ (with runs of $10^{6} \mathrm{MC}$ steps per atom at each temperature), in order to produce a sample of amorphous silica. The surfaces were then created by introducing a gap in the z-direction. Once put in contact with a thin film of crystalline $\mathrm{Ag}$ (the $\mathrm{Ag} /$ silica interactions are described with a van der Waals-like potential ${ }^{52,53}$ ), the silica layer is then heated to $3000 \mathrm{~K}$ for $10^{6} \mathrm{MC}$ steps, while the $\mathrm{Ag}$ film is kept rigid, to relax the two freshly 
cut silica surfaces. As previously, the temperature is then decreased step by step down to $300 \mathrm{~K}$.

In order to increase the statistics on the structural disorder of $\mathrm{SiO}_{2}, 3$ samples for each type of interface were prepared, which makes a total of 9 systems and $18 \mathrm{Ag} / \mathrm{SiO}_{2}$ interfaces (2 interfaces per system). The subsequent DFT relaxations were done in several steps, corresponding to loops of relaxation of the atomic positions followed by relaxation of the cell volume, until convergence of the total energy was reached. The threshold on the forces was set to $3 \mathrm{meV} / \AA$. After relaxation, the structural characteristics of the silica slabs have been analyzed and are reported in the Supporting Information. The most common observed defect are the edge-sharing tetrahedra (4 among 9 samples) and the three-coordinated oxygen atoms $\mathrm{OSi}_{3}$ (3 among 9 samples). The proportion of defects is reasonable given the small thickness of the $\mathrm{SiO}_{2}$ slabs. Since they are not located near the surfaces, they should not affect the properties of the interfaces. Regarding the distance and angle distributions, we observe a slight decrease of the $\mathrm{Si}-\mathrm{O}$ bond distance, of the O-O distance and of the $\widehat{S_{i O S}} i$ angles during relaxation. The pair correlation functions and angular distributions, although quite noisy because computed at $0 \mathrm{~K}$, are very similar to that of $\mathrm{SiO}_{2}$ slabs computed using AIMD, ${ }^{54}$ thus validating our protocol.

\section{Results}

After relaxation of the cell and of the atomic positions, we observed that the cell dimensions and the slab thicknesses are of the same order of magnitude for all samples and every facet (5 in Supporting Information). Note however that the (111) system is slightly larger in the $\mathrm{x}$ and $\mathrm{y}$-directions than the other ones. Among the 9 studied systems, we observed reconstructions taking place at $50 \%$ of the 18 investigated interfaces during relaxation. Indeed, after relaxation, for 9 interfaces among the 18 ones, one Si-O bond close to the interface breaks and new bonds form between the oxygen atoms and the silver atoms, and 
between the silicon atoms and the silver atoms. For some samples, both interfaces between $\mathrm{Ag}$ and $\mathrm{SiO}_{2}$ reconstruct, for some samples, only one interface and for others, there is no bond breaking (Tab. 5). We notice that the systems in which there is no bond breaking are the $\mathrm{Ag}(110) / \mathrm{SiO}_{2}$ ones which present the smallest silver atomic density at the interface. Note that these spontaneous reconstructions at the interfaces also take place in calculations in which the dispersion forces are not included (PBE calculations). After these relaxations, $a b$ initio molecular dynamics simulations have been carried out at $300 \mathrm{~K}$ for 3 ps and then at $500 \mathrm{~K}$ for another $3 \mathrm{ps}$ in the NVE ensemble, for two samples: one with a broken Si-O bond and one with no broken bonds. We did not observe additional bond breaking during these AIMD simulations, which indicates that the energy barriers to form new bonds are not very small.

The work of adhesion has been computed for all samples using:

$$
W_{a d}=\left[E\left(\mathrm{SiO}_{2}\right)+E(\mathrm{Ag})-E\left(\mathrm{Ag} / \mathrm{SiO}_{2}\right)\right] / 2 \mathrm{~A}
$$

where $E\left(\mathrm{SiO}_{2}\right)$ is the total energy of the $\mathrm{SiO}_{2}$ slab alone, $E(\mathrm{Ag})$ is the total energy of the $\mathrm{Ag}$ slab alone, $\mathrm{E}\left(\mathrm{Ag} / \mathrm{SiO}_{2}\right)$ is the total energy of the interface system and $\mathrm{A}$ is the area of the interface. Note that $\mathrm{W}_{a d}$ is the average value of the works of adhesion of the two interfaces in a given sample. $\mathrm{W}_{a d}$ is positive for all interfaces and varies between 292 and $550 \mathrm{~mJ} . \mathrm{m}^{-2}$ which indicates that silica and Ag have a moderate tendency to stick together (5 in Supporting Information). The large variations in $\mathrm{W}_{a d}$ are not correlated to the type of interface. By analyzing the number of bond breaking and forming for each sample, we noticed that it is correlated with the value of $\mathrm{W}_{a d}$. Indeed, the smallest values of $\mathrm{W}_{a d}$ are obtained for Samples 2 and 3 of $\mathrm{Ag}(110) / \mathrm{SiO}_{2}\left(326\right.$ and $\left.292 \mathrm{~mJ} . \mathrm{m}^{-2}\right)$ in which there are no interface bond. The highest values of $\mathrm{W}_{a d}$ are found for Sample 2 of $\mathrm{Ag}(100) / \mathrm{SiO}_{2}(579$ mJ.m $\left.{ }^{-2}\right)$ and Sample 1 of $\mathrm{Ag}(111) / \mathrm{SiO}_{2}\left(505 \mathrm{~mJ} . \mathrm{m}^{-2}\right)$ for which we observe the formation of interface bonds at each interface, and for Sample 1 of $\mathrm{Ag}(110) / \mathrm{SiO}_{2}\left(550 \mathrm{~mJ} . \mathrm{m}^{-2}\right)$ in which 
one $\mathrm{Si}-\mathrm{O}$ bond is broken and $\mathrm{Si}-\mathrm{Ag}$ and $\mathrm{O}-\mathrm{Ag}$ bonds are formed at one interface, and another $\mathrm{Si}-\mathrm{O}$ bond is about to break at the other interface. In summary, the formation of interface bonds leads to an increase of the $\mathrm{W}_{a d}$ of about 100 to $150 \mathrm{~mJ} . \mathrm{m}^{-2}$ per broken Si-O bond.

Experimentally, the work of adhesion of liquid silver on amorphous silica has been estimated at $174 \mathrm{~mJ} . \mathrm{m}^{-2} 55$ and at $430 \mathrm{~mJ} . \mathrm{m}^{-2}{ }^{56}$ by measuring the contact angle in wettability experiments. The discrepancy between these two values might be attributed to different experimental conditions and to the model used to derive the work of adhesion from contact angle measurements. The computed values of the present work are nevertheless in good agreement with these experimental estimates, thus validating our theoretical approach.

\section{Structural properties}

Table 2 presents selected geometrical characteristics after relaxation for the atoms involved in the interface reconstructions. The atom subscripts used in this table are given in Figure 3, where an example of Si-O bond breaking taking place at the interface is shown.
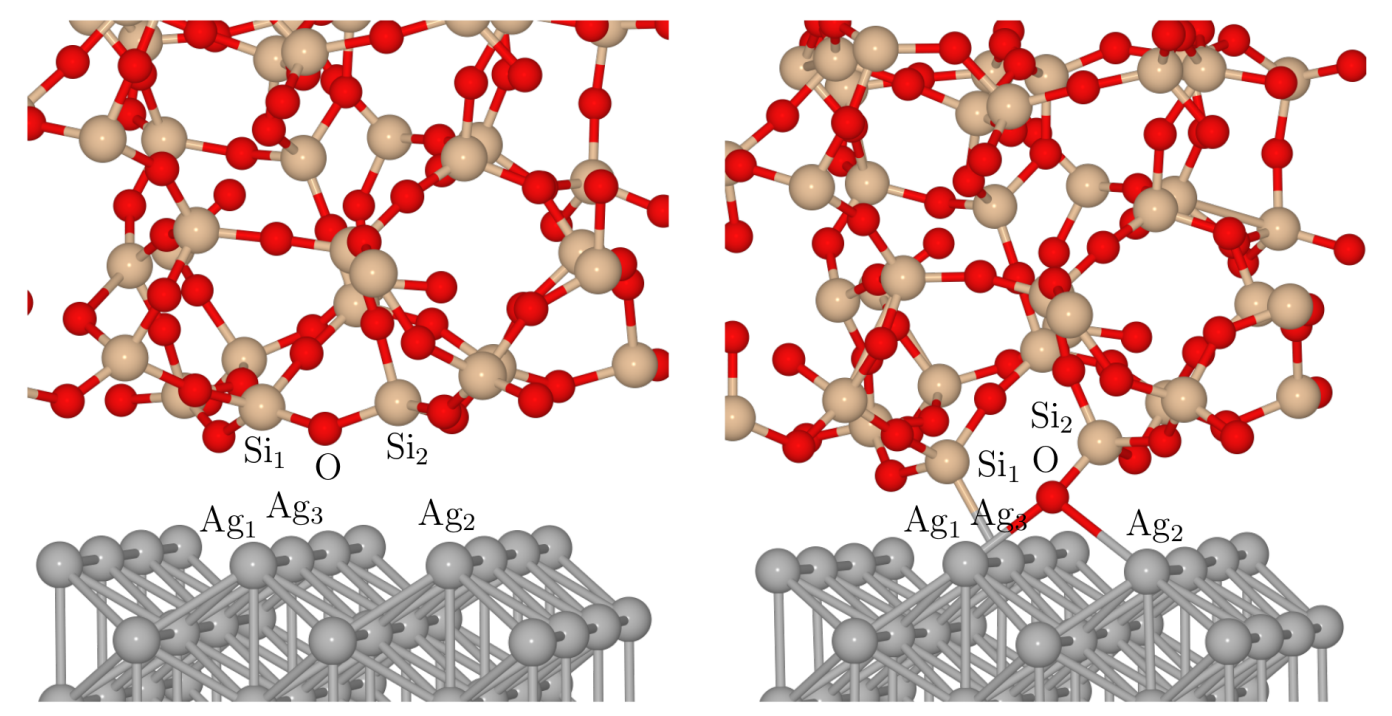

Figure 3: Example of a $\mathrm{Ag}(110) / \mathrm{SiO}_{2}$ interface before (left) and after (right) geometry optimization. The labels correspond to atoms involved in the interface reconstruction.

All the interface reconstructions present similar features: One $\mathrm{Si}-\mathrm{O}$ bond $\left(\mathrm{Si}_{1}-\mathrm{O}\right)$ close to the interface breaks during relaxation, the remaining $\mathrm{Si}-\mathrm{O}$ bond $\left(\mathrm{Si}_{2}-\mathrm{O}\right)$ becomes shorter 
Table 2: Interatomic distances (in $\AA$ ) of the bonds that are broken and/or created at the $\mathrm{Ag} / \mathrm{SiO}_{2}$ interfaces after the relaxation, $A \widehat{g_{1} O A} g_{2}$ in ${ }^{\circ}$ and size of the broken ring in $\mathrm{SiO}_{2}$.

\begin{tabular}{|c|c|c|c|c|c|c|c|c|}
\hline \hline & Sample & $\mathrm{d}_{O A g_{1}}$ & $\mathrm{~d}_{O A g_{2}}$ & ${A g_{1} O A g_{2}}$ & $\mathrm{~d}_{S i_{1} O}$ & $\mathrm{~d}_{S i_{2} O}$ & Ring size & $\mathrm{d}_{S i_{1} A g_{3}}$ \\
\hline & S1 & 2.34 & 2.39 & 77.3 & 3.07 & 1.59 & 3 & 2.48 \\
$\mathrm{Ag}(100) / \mathrm{SiO}_{2}$ & $\mathrm{~S} 21^{\text {st }}$ Bond & 2.33 & 2.53 & 74.4 & 3.10 & 1.59 & 4 & 2.49 \\
& $\mathrm{~S} 22^{\text {nd }}$ Bond & 2.39 & 2.24 & 81.5 & 3.36 & 1.59 & 3 & 2.47 \\
& $\mathrm{~S} 3$ & 2.26 & 2.41 & 79.7 & 3.15 & 1.58 & 6 & 2.46 \\
\hline \multirow{3}{*}{$\mathrm{Ag}(110) / \mathrm{SiO}_{2}$} & $\mathrm{~S} 1$ & 2.30 & 2.68 & 103.7 & 3.94 & 1.58 & 4 & 2.44 \\
& $\mathrm{~S} 2$ & - & - & - & - & - & - & - \\
& $\mathrm{S} 3$ & - & - & - & - & - & - & - \\
\hline & $\mathrm{S} 11^{\text {st }}$ Bond & 2.48 & 2.45 & 70.6 & 3.27 & 1.59 & 4 & 2.67 \\
$\mathrm{Ag}(111) / \mathrm{SiO}_{2}$ & $\mathrm{~S} 12^{\text {nd }}$ Bond & 2.47 & 2.23 & 78.4 & 3.14 & 1.58 & 4 & 2.41 \\
& $\mathrm{~S} 2$ & 2.19 & 2.71 & 72.7 & 3.00 & 1.59 & 3 & 2.48 \\
& $\mathrm{~S} 3$ & 2.28 & 2.36 & 80.4 & 3.96 & 1.59 & 4 & 2.58 \\
\hline \hline
\end{tabular}

(around $1.59 \AA$, Tab. 2) and the oxygen atom of the $\mathrm{Si}_{2}-\mathrm{O}$ bond approaches the silver surface (see Fig. 3). In most samples, this oxygen atom adopts a symmetric "bridge" position between two $\mathrm{Ag}$ atoms $\left(\mathrm{Ag}_{1}\right.$ and $\left.\mathrm{Ag}_{2}\right)$ of the silver surface with similar $\mathrm{d}_{O A g_{1}}$ and $\mathrm{d}_{O A g_{2}}$ distances, or a distorted one, if the two Ag-O distances are different (see Tab. 2). These Ag-O distances vary between $2.19 \AA$ and $2.71 \AA$. This is to compare with the Ag-O bond length of $2.048 \AA$ in $\mathrm{Ag}_{2} \mathrm{O}^{57}$ and with the typical $\mathrm{Ag}$-O bond lengths found in small $\mathrm{Ag}_{n}-\mathrm{O}_{2}$ clusters ${ }^{58}$ which range between $\sim 2.2$ and $2.6 \AA$. The values of the $\widehat{A g_{1} \widehat{O A}} g_{2}$ angles reflect that the $\mathrm{O}$ bridges two first neighbors $\mathrm{Ag}$ atoms on the $\mathrm{Ag}(100)$ and $\mathrm{Ag}(111)$ surfaces (between $70.6^{\circ}$ and $81.5^{\circ}$ ) and adsorbs on the long-bridge position on the $\mathrm{Ag}(110)$ surface $\left(103.7^{\circ}\right)$. The Si-O bond breaking has not only induced the formation of Ag-O bonds but also the creation of a $\mathrm{Si}-\mathrm{Ag}$ one. Indeed, the 3 -fold coordinated $\mathrm{Si}$ atom $\left(\mathrm{Si}_{1}\right)$ approaches the silver surface and adopts a position close to a "top" position above a third Ag atom $\left(\mathrm{Ag}_{3}\right)$. Depending on the initial position of the broken $\mathrm{Si}-\mathrm{O}$ bond with respect to the $\mathrm{Ag}$ atoms of the interface, the final $\mathrm{Si}-\mathrm{Ag}_{3}$ distance lies between $2.41 \AA$ and $2.67 \AA$. The experimental $\mathrm{Si}-\mathrm{Ag}$ bond length is found to be $2.40 \AA$ in silver silicides,${ }^{59}$ and theoretical estimates based on DFT calculations of the $\mathrm{Si}-\mathrm{Ag}$ bond lengths in $\mathrm{AgSi}$ and $\mathrm{AgSi}_{2}$ give values of $2.36 \AA$ and 
$2.48 \AA$, respectively. ${ }^{60}$

It is interesting to note that almost all $\mathrm{Si}-\mathrm{O}$ bond breakings take place for $\mathrm{Si}$ and $\mathrm{O}$ atoms belonging to a 3- or 4-membered ring, except for Sample 3 of $\mathrm{Ag}(100) / \mathrm{SiO}_{2}$. The ring size distribution in the $\mathrm{SiO}_{2}$ thin films of the present study (centered on 4- and 5-membered rings) is slightly shifted towards smaller rings than that of bulk amorphous silica which exhibits a majority of 5- and 6-membered rings (see 8 in Supporting Information). This shift can be due to the high cooling rate, to the small size of the silica samples and/or to the presence of the surface. ${ }^{54}$ Nevertheless, the correlation between small rings and the Si-O bond breaking at the interface is most likely significant.

\section{Electronic structure}

The total (TDOS) and partial ( $\mathrm{Si}, \mathrm{O}$ and $\mathrm{Ag}$ ) density of states (DOS) for two different samples, with and without bond breaking, are depicted in Figure 4. In all samples, we observe similar features: the highest occupied states are dominated by the $\mathrm{Ag} d$-states and by the $\mathrm{O} p$-states, and the main bands of amorphous $\mathrm{SiO}_{2}$ are clearly recognizable in the range [-10;-3] eV. ${ }^{61}$ By looking carefully at the magnification of the partial DOS, one can observe small peaks in the O DOS at $\approx-2.5 \mathrm{eV}$, which are present only in samples where a reconstruction occurred (Sample 1, left panels in Fig. 4). Indeed, in the DOS of Sample 3 of $\mathrm{Ag}(110) / \mathrm{SiO}_{2}$ (right panels in Fig. 4), in which no reconstruction was observed, these small peaks are absent. These peaks could be a signature of the bonding between the oxygen atom involved in the bond breaking and the Ag atoms of the interface.

In order to verify this hypothesis, we show in Fig. 5 examples of the DOS projected on the specific atoms (PDOS) involved in the interface reconstructions. Indeed, the existence of bonding between atoms at the interface can be verified by looking at overlaps of the projected densities of states. In the three examples depicted in Fig. 5, there is a clear overlap between the PDOS of the $\mathrm{O}$ atom and that of its two $\mathrm{Ag}$ neighbours, $\mathrm{Ag}_{1}$ and $\mathrm{Ag}_{2}$, around $-2.5 \mathrm{eV}$ (upper panels). This is a signature of a bonding between these atoms. Overlaps between 
$\mathrm{Ag}(110) / \mathrm{SiO}_{2}$ Sample 1

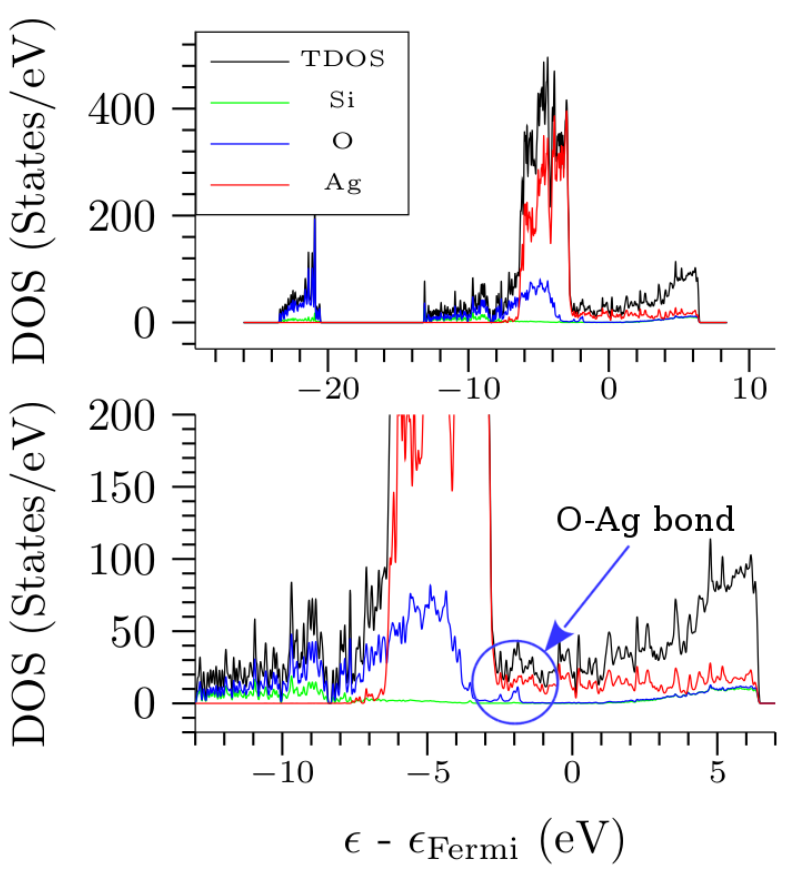

$\mathrm{Ag}(110) / \mathrm{SiO}_{2}$ Sample 3

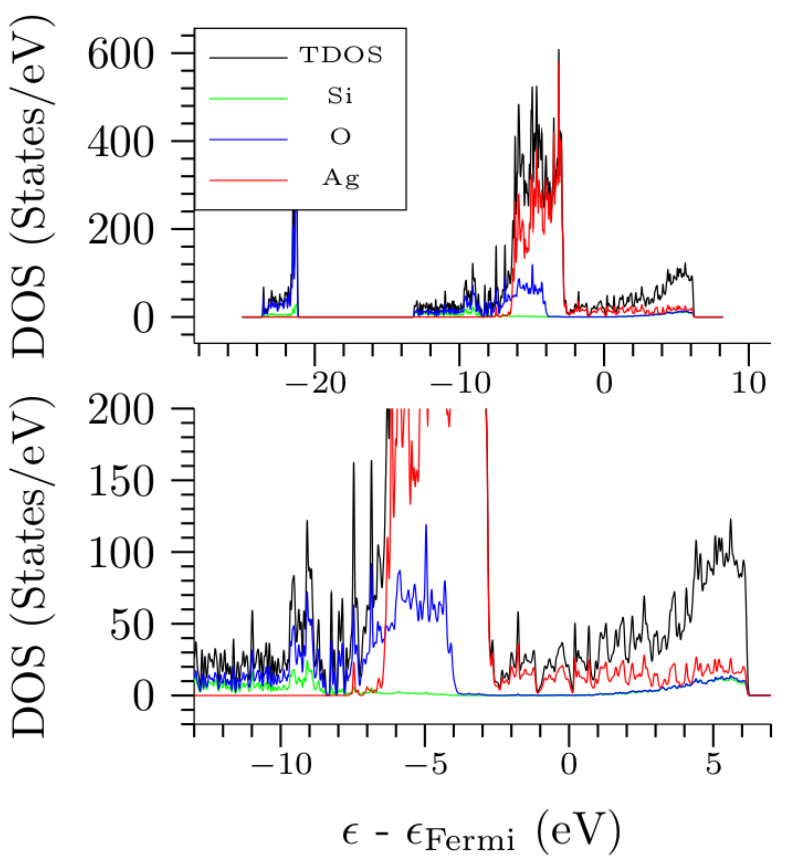

Figure 4: Examples of total (TDOS) and partial density of states ( $\mathrm{Si}, \mathrm{O}, \mathrm{Ag}$ ) of $\mathrm{Ag} / \mathrm{SiO}_{2}$ systems: Sample 1 of $\mathrm{Ag}(110) / \mathrm{SiO}_{2}$ and Sample 3 of $\mathrm{Ag}(110) / \mathrm{SiO}_{2}$. The lower panels are magnifications of the $-13 \mathrm{eV}$ to $7 \mathrm{eV}$ energy range. A gaussian smoothing function of $\sigma=0.5$ $\mathrm{eV}$ has been used.

the PDOS of the $\mathrm{O}$ atom and the $\mathrm{Si}_{2}$ atom are also visible between -6.0 and $-7.0 \mathrm{eV}$ (middle panels), which is a signature of the remaining bond between these two atoms. In addition, one can observe small peaks in the $\mathrm{Si}_{1}$ atom PDOS between -1.0 and -2.0 eV which overlap with the $\mathrm{Ag}_{3}$ PDOS (bottom panels), indicating a bond between these atoms as well. All these features are present for the atoms involved in all the reconstructed interfaces (not shown).

\section{Charge distribution}

To investigate the charge re-organization at the interface, we computed the Bader atomic charges for the 9 investigated samples. In Tab. 3 are gathered the charges on the atoms involved in the interface reconstructions. For comparison, note that the average charge values for the $\mathrm{Si}, \mathrm{O}$ and $\mathrm{Ag}$ atoms are $+3.17 e,-1.60 e$ and $0.00 e$ respectively in these samples. 

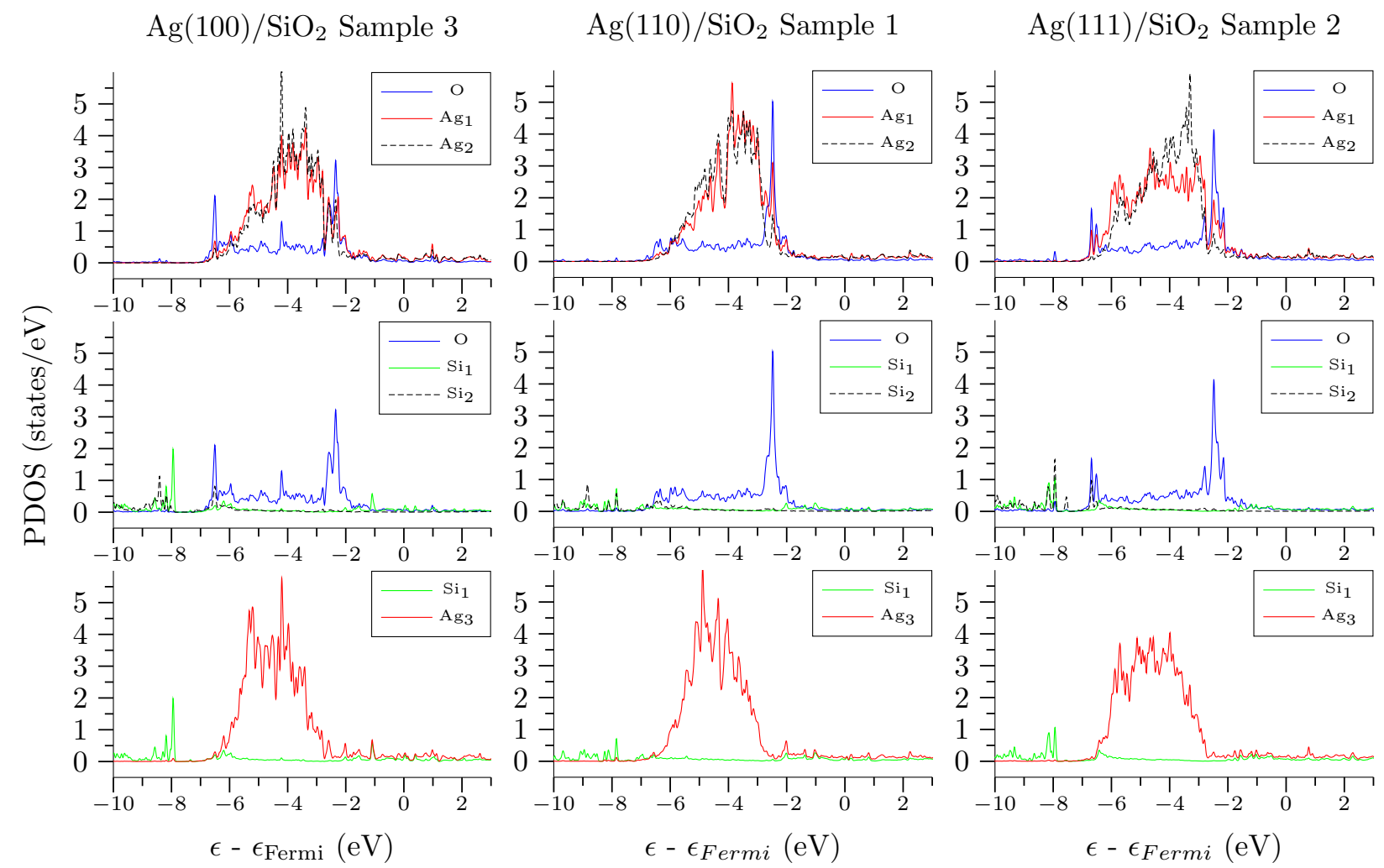

Figure 5: Examples of Projected Density of States (PDOS) on the atoms involved in the bonds formation at the $\mathrm{Ag} / \mathrm{SiO}_{2}$ interfaces.

After the relaxation, in all samples, the remaining $\mathrm{Si}_{2}-\mathrm{O}$ bond length becomes quite short (1.58-1.59 $\AA$ ) but the $\mathrm{Si}_{2}$ charge does not significantly change (between $+3.13 e$ and +3.18 $e$ ). On the opposite, one of the shared electrons of the broken $\mathrm{Si}_{1}-\mathrm{O}$ bond transfers to the $\mathrm{Si}_{1}$ atom. Indeed its charge ranges between +2.38 and $+2.10 e$, which corresponds to an excess charge of $\sim-0.79 /-1.07 e$ on these atoms compared to the average value for $\mathrm{Si}$ atoms in the samples. The $\mathrm{O}$ atom which participates to bonds with two $\mathrm{Ag}$ atoms in a bridge configuration has a charge between -1.40 and -1.45 e, i.e. $\approx 0.20 e$ less charged than the average value for the $\mathrm{O}$ atoms in $\mathrm{SiO}_{2}$. The $\mathrm{Ag}$ atoms bonded to this oxygen atom become more positively charged $(\approx+0.15 e)$ and the $\mathrm{Ag}_{3}$ atom close to the $\mathrm{Si}_{1}$ atoms becomes more negatively charged (between -0.02 and $-0.17 e$ ) with respect to the average value. The charge transfers on the oxygen atom and on the $\mathrm{Ag}_{1}, \mathrm{Ag}_{2}$ and $\mathrm{Ag}_{3}$ atoms are not sufficient to compensate the excess charge on the $\mathrm{Si}_{1}$ atom. Indeed, we also observe a slight excess 
charge spread over the Ag atoms around the ones involved in the Ag-O and Si-O bonds.

The configuration of $\mathrm{Si}_{1}$ in which the $\mathrm{Si}$ atom is bonded to only 3 oxygen atoms and bears an additional electron is very similar to that of a well-known defect in $\mathrm{SiO}_{2}$, made of a 3-coordinated charged $\mathrm{Si}\left(\mathrm{SiO}_{3}^{-}\right)$, called $\mathrm{E}$ ' center. ${ }^{62}$ This defect is made of an oxygen vacancy and a silicon dangling bond with an unpaired electron. Several types of E' centers exist which differ from each other by their structure. These defects are responsible for the performance drop of electronic and optical devices. For instance, the existence of E' centers is associated with the appearance of an absorption band at $5.8 \mathrm{eV}$ in the UV range. Due to the unpaired electron, they are detectable by EPR (electron paramagnetic resonance) and some of them $\left(\mathrm{E}_{\gamma}^{\prime}\right.$ and $\mathrm{E}_{\alpha}{ }_{\alpha}$, for instance) give rise to a strong hyperfine coupling. ${ }^{62}$

Note that, in the experiments conducted in our group ${ }^{24}$ significant numbers of defects in $\mathrm{SiO}_{2}$ are created during ion implantation. These defects, due to the displacement of ions, create vacancy related centers such as E' centers or bond breaking which gives rise to $\mathrm{SiO}$ dangling bond centers (such as NBOHC). ${ }^{63}$ The analysis of EPR spectra of E'-centers for amorphous $\mathrm{SiO}_{2}$ implanted with different ions including $\mathrm{Ag}^{+}$, shows that, in the implantation layer, E' centers indeed co-exist with different degrees of local environmental distortion. ${ }^{64}$ In implanted silica, damage recovery starts at $\mathrm{T}>500^{\circ} \mathrm{C}$, with irreversible $\mathrm{E}$ ' centers annealing due to oxygen diffusion and capture and peroxy radical or peroxyl bridge dissociation. ${ }^{63} \mathrm{~A}$ total recovering of the silica matrix is observed after annealing at high temperature (1100 $\left.{ }^{\circ} \mathrm{C}\right) .{ }^{65}$ In Ref., ${ }^{24}$ the $\mathrm{Ag}^{+}$implanted layers have been annealed under $\mathrm{N}_{2}$ atmosphere at $500{ }^{\circ} \mathrm{C}$ for 30 minutes. At such low thermal budget only a partial damage recovering is observed. ${ }^{29}$ In the model samples, the silica layers do not exhibited the defects due the ion implantation damage. Therefore these E' centers could only be expected at the interface between $\mathrm{SiO}_{2}$ and $\mathrm{Ag}$.

In order to verify whether the 3 -coordinated $\mathrm{Si}_{1}$ atom observed at the interface is indeed an E' center, we have estimated the hyperfine coupling on the $\mathrm{Si}_{1}$ atom both in the $\mathrm{SiO}_{2} / \mathrm{Ag}$ interface sample and in the corresponding $\mathrm{SiO}_{2}$ slab, in the absence of the $\mathrm{Ag}$ slab. In this 
latter case, the calculation was performed using the coordinates of $\mathrm{SiO}_{2}$ in the $\mathrm{Ag} / \mathrm{SiO}_{2}$ interface, i.e. with the 3 -coordinated $\mathrm{Si}_{1}$ atom. The calculations show a significant hyperfine coupling on the $\mathrm{Si}_{1}$ atom in the case of the free $\mathrm{SiO}_{2}$ slab, but this coupling disappears when the $\mathrm{SiO}_{2}$ is put in contact with the $\mathrm{Ag}$ slab. This is probably due to the fact that the electron on the $\mathrm{Si}_{1}$ atom is no more unpaired once in contact with the $\mathrm{Ag}$ surface. In order to check this assumption, we analyzed the Bader volumes associated with the atoms involved in the reconstruction. The Bader volume is defined as the volume around each atom in which the charge density is integrated to compute the Bader charge. Its boundary is determined as the surface through which the charge density gradient has a zero flux. In the left panel of Fig. 6, we show an example of these Bader volumes for the $\mathrm{Si}_{1}$ atom and its neighbors. One can clearly see the large Bader volume associated with the $\mathrm{Si}_{1}$ atom (yellow) which spreads towards that of the $\mathrm{Ag}_{3}$ atom (grey). This indicates the covalent nature of the bond between $\mathrm{Si}_{1}$ and $\mathrm{Ag}_{3}$. In this bond, however, the electrons go preferentially on the $\mathrm{Si}_{1}$ atom, as evidenced by the large number of electrons on this atom (Tab. 3).
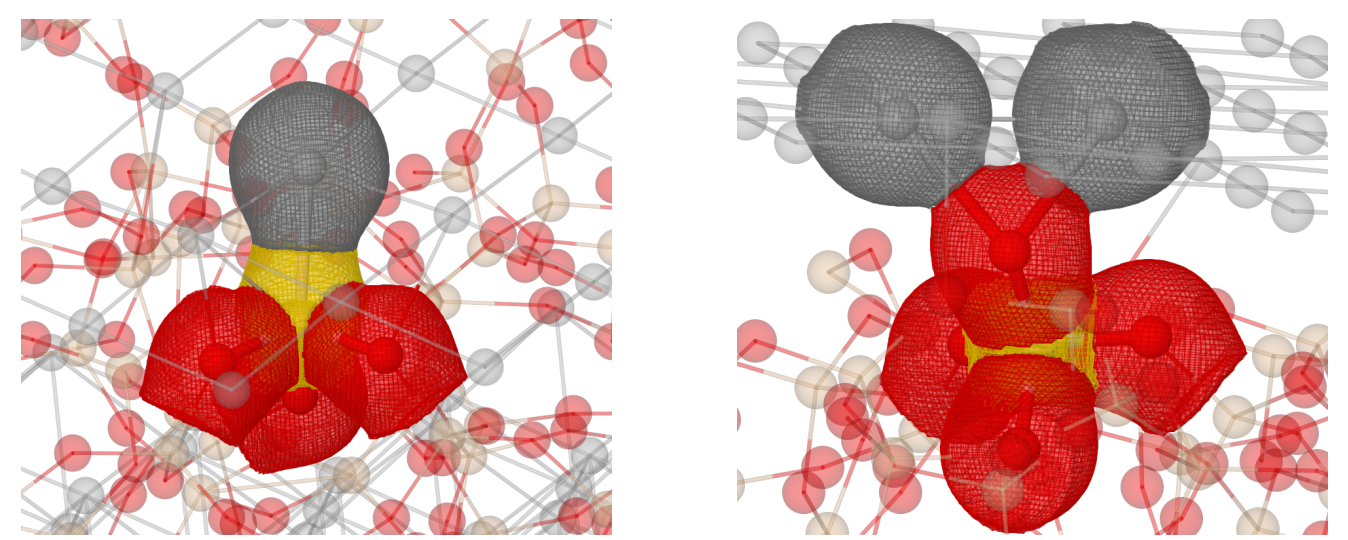

Figure 6: Bader volumes around the atoms involved in the interface bonding (Sample 1 of $\left.\mathrm{Ag}(110) / \mathrm{SiO}_{2}\right)$. Left panel: $\mathrm{Si}_{1}-\mathrm{Ag}_{3}$ bond; Right panel: $\mathrm{O}-\mathrm{Ag}_{1}$ and $\mathrm{O}-\mathrm{Ag}_{2}$ bonds. Grey: $\mathrm{Ag}$, yellow: $\mathrm{Si}$ and red: $\mathrm{O}$.

For comparison, we show on the right panel of Fig. 6, the Bader volumes of the oxygen atom bonded to the two Ag atoms at the interface and that of its neighbors. Here as well, the Bader volume of the $\mathrm{O}$ atom extends towards that of the $\mathrm{Ag}$ atoms. The contact surface between these volumes is significant, indicating a partially covalent bonding. 
Table 3: Bader charges (in $e$ ).

\begin{tabular}{|l|c|r|r|r|r|r|r|}
\hline \hline & Sample & $\mathrm{O}$ & $\mathrm{Si}_{1}$ & $\mathrm{Si}_{2}$ & $\mathrm{Ag}_{1}$ & $\mathrm{Ag}_{2}$ & $\mathrm{Ag}_{3}$ \\
\hline & $\mathrm{S} 1$ & -1.43 & +2.10 & +3.15 & +0.16 & +0.17 & -0.04 \\
$\mathrm{Ag}_{100} / \mathrm{SiO}_{2}$ & $\mathrm{~S}^{\text {st }} 1^{\text {st }}$ bond & -1.42 & +2.19 & +3.16 & +0.19 & +0.13 & -0.02 \\
& $\mathrm{~S}^{2} 2^{\text {nd }}$ bond & -1.41 & +2.13 & +3.13 & +0.19 & +0.17 & -0.06 \\
& $\mathrm{~S} 3$ & -1.42 & +2.25 & +3.15 & +0.21 & +0.18 & -0.10 \\
\hline \multirow{3}{*}{$\mathrm{Ag}_{110} / \mathrm{SiO}_{2}$} & $\mathrm{~S} 1$ & -1.45 & +2.21 & +3.15 & +0.22 & +0.14 & -0.08 \\
& $\mathrm{~S} 2$ & - & - & - & - & - & - \\
& $\mathrm{S} 3$ & - & - & - & - & - & - \\
\hline & $\mathrm{S} 11^{\text {st }}$ bond & -1.42 & +2.23 & +3.16 & +0.14 & +0.14 & -0.05 \\
$\mathrm{Ag}_{111} / \mathrm{SiO}_{2}$ & $\mathrm{~S}^{\text {nd }}$ bond & -1.41 & +2.38 & +3.15 & +0.13 & +0.14 & -0.17 \\
& $\mathrm{~S} 2$ & -1.43 & +2.34 & +3.17 & +0.16 & +0.11 & -0.12 \\
& $\mathrm{~S} 3$ & -1.40 & +2.19 & +3.18 & +0.14 & +0.13 & -0.04 \\
\hline \hline
\end{tabular}

\section{Discussion}

These results evidences that the interface between a silver surface and a silica slab exhibits covalent bonds between both the $\mathrm{Si}$ and $\mathrm{Ag}$ atoms and the $\mathrm{O}$ and $\mathrm{Ag}$ atoms. Depending on our initial $\mathrm{SiO}_{2}$ structure and the type of the Ag facet, we observe a different number of bonds at the interface. The $\operatorname{Ag}(100)$ and $\operatorname{Ag}(111)$ facets give rise to a higher number of interface bonds than the $\operatorname{Ag}(110)$ one. This is attributed to the fact that the density of surface $\mathrm{Ag}$ atoms is lower on this facet $\left(0.09\right.$ at. $\left./ \AA^{2}\right)$ than on the other ones $\left(0.12\right.$ at. $/ \AA^{2}$ and 0.14 at. $\left./ \AA^{2}\right)$. Indeed, the formation of bonds at the interface seems to depend on geometric factors such as the proximity of a $\mathrm{Si}$ atom and an $\mathrm{Ag}$ atom and the possibility for the $\mathrm{O}$ atom to move into a bridge position between two $\mathrm{Ag}$ atoms. The greater the number of $\mathrm{Ag}$ atoms at the interface, the higher the probability that this configuration exists.

Regarding the initial structure of the samples before relaxation, we noticed that the ones that present interface bonds share common features. First of all, the initial Bader charge on the $\mathrm{Si}_{1}$ atom (see Fig. 3), lying between +3.13 and $+2.97 e$ with an average value of $+3.05 e$, is lower than the average $\mathrm{Si}$ charge $(+3.17 \mathrm{e})$. Moreover, the $\mathrm{Si}_{1}$ atom always bears the lowest charge among the $\mathrm{Si}$ atoms of the interface. In $78 \%$ of the cases, the $\mathrm{Si}_{1}$ atom is one of the 
closest atoms with respect to the $\mathrm{Ag}$ surface (the $\mathrm{Si}_{1}-\mathrm{Ag}_{3}$ distances before relaxation lying between $2.98 \AA$ and $3.54 \AA$ with an average value of $3.18 \AA$ ). Regarding the initial $\mathrm{O}-\mathrm{Ag}_{1,2}$ distance, it is the smallest one in $66 \%$ of the cases (the O-Ag distances before relaxation lying between $2.51 \AA$ and $3.04 \AA$ with an average value of $2.82 \AA$ ). Note that the initial distances between the $\mathrm{SiO}_{2}$ and the $\mathrm{Ag}$ slabs, and consequently the initial charges depend on the simulation protocol used to generate the systems. Therefore their absolute values must be taken with caution, the only significant information being the fact that the reactive sites are the closest ones to the Ag surface and the Si ones having the higher number of electrons. However, the initial structure of the silica surface does not seem to play a significant role in the occurrence of a Si-O bond breaking at the interface. Indeed, we could not find any correlation between the characteristics of the Si-O bond and its environment (bond length, Si-O-Si angle, ring size etc.) and its probability to break.

It has been experimentally evidenced that the work of adhesion of liquid metals on silica can only be accounted for by the presence of covalent bonds between the metal and the oxide in addition to van der Waals interaction. ${ }^{55}$ In the case of silver, the experimental work of adhesion is rather low but still compatible with the existence of covalent bonds between the metal and the silica surface. ${ }^{55,56}$ In our simulations, the surface reconstructions are observed at zero temperature for a dry silica matrix thus indicating that no activation energy is needed to break the Si-O bond and form the interfacial Si-Ag and O-Ag bonds. In the present model, the silica surfaces are not hydroxylated whereas, in ambient conditions, the silica surface is terminated by silanol groups ( $\mathrm{Si}-\mathrm{O}-\mathrm{H})$ which saturates the Si-O dangling bonds. The concentration of these groups at the surface depends on the air humidity and on the temperature and has been estimated to be between 4 and $6 \mathrm{OH} / \mathrm{nm}^{2}$ in water saturation conditions at room temperature. ${ }^{30}$ At a temperature of $400{ }^{\circ} \mathrm{C}$, it is around $2 \mathrm{OH} / \mathrm{nm}^{2}$ and the silica surface is fully dehydroxylated around $1000^{\circ} \mathrm{C}$. Thus one can assume that, in the presence of $\mathrm{Si}-\mathrm{O}-\mathrm{H}$ at the interface, the metal has to replace the hydrogen atoms or the hydroxyl groups to form interfacial bonds with silica. Besides, recent studies have shown 
that metal silicides can be created via direct interaction between $\mathrm{SiO}_{2}$ and the metal. ${ }^{66}$

In our embedded AgNPs synthesis, ${ }^{24}$ low energy ion implantation into $\mathrm{SiO}_{2}$ causes a damaged surface layer. The high number of broken bonds due to displaced Si and O atoms create defects in the glassy network in which water from the atmosphere can diffuse. ${ }^{67}$ This water incorporation from the ambient during the ion beam synthesis of nanocrystals has been studied by hydrogen depth profiling using nuclear reaction analysis (NRA). ${ }^{68}$ Concentrations of hydrogen up to 10 at. \% due to water absorption from the ambient were measured in the implanted region but massive exodiffusion of $\mathrm{H}$ takes place during subsequent annealing at temperatures as low as $600^{\circ} \mathrm{C}$. In the case of $\mathrm{Ag}^{+}$implanted silica, annealing of the layers at low temperature $\left(400-500^{\circ} \mathrm{C}\right)$ under $\mathrm{N}_{2}$ allows a partial recovering of the implantation damage and therefore delays and reduces the penetration of O-rich complexes as evidenced by the absence of ageing by oxidation process of the AgNPs, even after some months. ${ }^{29}$ Following the Zhuravlev model, ${ }^{30}$ at $400{ }^{\circ} \mathrm{C}$, the silanol concentration on the silica surface is below $2 \mathrm{OH} / \mathrm{nm}^{2}$. More recently, Gierada et al. ${ }^{69}$ have proposed a new model which gives a concentration between $3.6 \mathrm{OH} / \mathrm{nm}^{2}$ and $1.7 \mathrm{OH} / \mathrm{nm}^{2}$ for water pressure from $10^{-} 2$ to $10^{-} 9$ atm, at $400^{\circ}$. One can thus assume that the silica is only poorly hydroxylated at the interface with the nanoparticles, validating the choice of a dehydroxylated silica surface in our models. The limited sizes of these model systems do not allow to define precisely the concentration of metal-silica interfacial bonds. In systems where we observe these bonds, a maximum of one Si-O bond breaks on an interface area between $\sim 141$ and $216 \AA^{2}$ and 2 Ag-O bonds and $1 \mathrm{Ag}-\mathrm{Si}$ bond are formed, corresponding to 1.5 to 2.2 interface bonds $/ \mathrm{nm}^{2}$.

In summary, we can assume that the silica matrix is most probably dehydroxylated -at least partially- after implantation and annealing, and that the interface between the implanted $\mathrm{AgNP}$ and the silica matrix is largely composed of $\mathrm{Si}-\mathrm{Ag}$ and $\mathrm{O}-\mathrm{Ag}$ bonds. This knowledge of the surface state of implanted AgNPs is particularly important for understanding the elementary mechanisms at play during the first steps of the $\mathrm{Ag}^{+}$release. ${ }^{24}$ In particular, it is worth wondering whether the $\mathrm{O}-\mathrm{Ag}$ bonds that are formed at the interface 
could be involved in the detachment mechanism of Ag atoms from the surface of AgNPs embedded in a silica matrix. In solution, the current consensus presents the oxidative dissolution mechanism by $\mathrm{O}_{2}$ as the main mechanism leading to the detachment of an $\mathrm{Ag}$ atom from a $\mathrm{Ag}$ nanoparticle, at the origin of the $\mathrm{Ag}^{+}$release. One can wonder whether the first steps of the AgNP dissolution are retained when embedded in a dielectric matrix, or if the initial silver oxidation occurs through a different mechanism. Indeed, the presence of Ag-O bonds at the interface could replace the effect of $\mathrm{O}_{2}$ and initiate the Ag detachment.

\section{Conclusion}

Interfaces between amorphous silica and the most stable crystalline facets of silver have been modelled by periodic DFT calculations in the PBE approximation with a dispersion correction of the Grimme-D3 type. The preparation of the systems, in particular the amorphous silica slabs, has been carried out using empirical potentials. The relaxation of the atomic positions in the DFT framework leads to reconstructions in $50 \%$ of the interfaces, which consist in a breaking of a Si-O bond and the formation of two O-Ag bonds and one Si-Ag bond at the interface. The work of adhesion of these interfaces is found to be of the same order of magnitude than the experimental values derived from wettability experiments. The analysis of the electronic density of states has evidenced the covalent nature of the bonds between $\mathrm{O}$ and $\mathrm{Ag}$ and between $\mathrm{Si}$ and Ag. Bader charge estimates have shown that the shared electron in the Si-O bond goes preferentially on the Si atom after the interface reconstruction.

These results tell us that spontaneous covalent bonds form at the interface between a dehydroxylated silica surface and a silver nanoparticle, whatever the facet. This situation corresponds to devices fabricated by us using ionic implantation and annealed at high temperature in which the number of $\mathrm{OH}$ per $\mathrm{nm}^{2}$ at the silica surface is expected to be quite low. In this specific context, we assume that the nature of the interface between AgNPs and silica is made of covalent bonding and that some Ag surface atoms are partially oxidized. 
The existence of these interface bonds is likely to have an impact on the detachment of silver atoms from the nanoparticle surface, which is expected to be the first step of the $\mathrm{Ag}^{+}$ release. However, from our results, it is difficult to say whether this can promote or hinder the detachment. To further investigate, it is necessary to study in more detail the reactivity of these interfaces in temperature and in the presence of other chemical species such as water or $\mathrm{O}_{2}$.

In any case, one can not totally rule out the presence of silanol groups at the silica surface. In this situation, the replacement of the $\mathrm{H}$ atoms and/or the $\mathrm{OH}$ groups by $\mathrm{Ag}$ atoms would be required in order to form the $\mathrm{Ag}-\mathrm{O}$ and $\mathrm{Si}-\mathrm{O}$ interface bonds. Besides, the AgNPs present edges and corners where the Ag atoms are under-coordinated which is not taken into account in the present study. The influence of these atoms on the interface reconstruction should also be investigated.

\section{Acknowledgement}

This work was performed using HPC resources from CALMIP (Grant p17024) and from GENCI (Grant A0040910409). It was supported by a CNRS Defi INFINITI Grant (MIRAGE project) and a Labex NEXT Grant (MAGIC project). The authors thank K. Makasheva, P. Benzo and F. Gourbilleau for fruitful discussions.

\section{References}

(1) Chernousova, S.; Epple, M. Angewandte Chemie International Edition 2013, 52, 16361653.

(2) Prabhu, S.; Poulose, E. K. International Nano Letters 2012, 2, 32.

(3) Zheng, K.; Setyawati, M. I.; Leong, D. T.; Xie, J. Coordination Chemistry Reviews 2018, 357, 1-17. 
(4) Smith, J. N.; Thomas, D. G.; Jolley, H.; Kodali, V. K.; Littke, M. H.; Munusamy, P.; Baer, D. R.; Gaffrey, M. J.; Thrall, B. D.; Teeguarden, J. G. Particle and Fibre Toxicology 2018, 15, 47.

(5) Molleman, B.; Hiemstra, T. Langmuir 2015, 31, 13361-13372.

(6) Sotiriou, G. A.; Meyer, A.; Knijnenburg, J. T. N.; Panke, S.; Pratsinis, S. E. Langmuir 2012, 28, 15929-15936.

(7) Xiu, Z.-m.; Zhang, Q.-b.; Puppala, H. L.; Colvin, V. L.; Alvarez, P. J. J. Nano Letters 2012, 12, 4271-4275.

(8) Molleman, B.; Hiemstra, T. Environmental Science: Nano 2017, 4, 1314-1327.

(9) Le Ouay, B.; Stellacci, F. Nano Today 2015, 10, 339-354.

(10) Suresh, A. K.; Pelletier, D. A.; Wang, W.; Moon, J.-W.; Gu, B.; Mortensen, N. P.; Allison, D. P.; Joy, D. C.; Phelps, T. J.; Doktycz, M. J. Environmental Science $\&$ Technology 2010, 44, 5210-5215.

(11) Navarro, E.; Piccapietra, F.; Wagner, B.; Marconi, F.; Kaegi, R.; Odzak, N.; Sigg, L.; Behra, R. Environmental Science \& Technology 2008, 42, 8959-8964.

(12) Fabrega, J.; Renshaw, J. C.; Lead, J. R. Environmental Science \& Technology 2009, 43, 9004-9009.

(13) Allen, H. J.; Impellitteri, C. A.; Macke, D. A.; Heckman, J. L.; Poynton, H. C.; Lazorchak, J. M.; Govindaswamy, S.; Roose, D. L.; Nadagouda, M. N. Environmental Toxicology and Chemistry 2010, 29, 2742-2750.

(14) Juarez-Moreno, K.; Gonzalez, E.; Girón-Vazquez, N.; Chàvez-Santoscoy, R.; MotaMorales, J.; Perez-Mozqueda, L.; Garcia-Garcia, M.; Pestryakov, A.; Bogdanchikova, N. Human $\&$ Experimental Toxicology 2017, 36, 931-948. 
(15) Liu, J.; Sonshine, D. A.; Shervani, S.; Hurt, R. H. ACS Nano 2010, 4, 6903-6913.

(16) Ho, C.-M.; Wong, C.-K.; Yau, S. K.-W.; Lok, C.-N.; Che, C.-M. Chemistry - An Asian Journal 2011, 6, 2506-2511.

(17) Loza, K.; Diendorf, J.; Sengstock, C.; Ruiz-Gonzalez, L.; Gonzalez-Calbet, J. M.; Vallet-Regi, M.; Köller, M.; Epple, M. Journal of Materials Chemistry B 2014, 2, 1634.

(18) Hanske, C.; Sanz-Ortiz, M. N.; Liz-Marzán, L. M. Advanced Materials 2018, 30, 1707003.

(19) Sotiriou, G. A.; Sannomiya, T.; Teleki, A.; Krumeich, F.; Vörös, J.; Pratsinis, S. E. Advanced Functional Materials 2010, 20, 4250-4257.

(20) Hu, Y.; Shi, Y.; Jiang, H.; Huang, G.; Li, C. ACS Applied Materials \& Interfaces 2013, 5, 10643-10649.

(21) Yang, S.-A.; Choi, S.; Jeon, S. M.; Yu, J. Sci Rep 2018, 8, 185.

(22) Granbohm, H.; Larismaa, J.; Ali, S.; Johansson, L.-S.; Hannula, S.-P. Materials 2018, 11,80 .

(23) Kim, T.-G.; Kim, Y. W.; Kim, J. S.; Park, B. Journal of Materials Research 2004, 19, 1400-1407.

(24) Pugliara, A.; Makasheva, K.; Despax, B.; Bayle, M.; Carles, R.; Benzo, P.; BenAssayag, G.; Pécassou, B.; Sancho, M. C.; Navarro, E.; Echegoyen, Y.; Bonafos, C. Science of The Total Environment 2016, 565, 863-871.

(25) Benzo, P.; Bonafos, C.; Bayle, M.; Carles, R.; Cattaneo, L.; Farcau, C.; Benassayag, G.; Pécassou, B.; Muller, D. Journal of Applied Physics 2013, 113, 193505. 
(26) Ewing, C. S.; Hartmann, M. J.; Martin, K. R.; Musto, A. M.; Padinjarekutt, S. J.; Weiss, E. M.; Veser, G.; McCarthy, J. J.; Johnson, J. K.; Lambrecht, D. S. The Journal of Physical Chemistry C 2015, 119, 2503-2512.

(27) Ewing, C. S.; Veser, G.; McCarthy, J. J.; Johnson, J. K.; Lambrecht, D. S. The Journal of Physical Chemistry C 2015, 119, 19934-19940.

(28) Tielens, F.; Gierada, M.; Handzlik, J.; Calatayud, M. Catalysis Today 2019,

(29) Benzo, P.; Cattaneo, L.; Farcau, C.; Andreozzi, A.; Perego, M.; Benassayag, G.; Pécassou, B.; Carles, R.; Bonafos, C. Journal of Applied Physics 2011, 109, 103524.

(30) Zhuravlev, L. Colloids and Surfaces A: Physicochemical and Engineering Aspects 2000, $173,1-38$.

(31) Ewing, C. S.; Bhavsar, S.; Veser, G.; McCarthy, J. J.; Johnson, J. K. Langmuir 2014, 30, 5133-5141.

(32) González, A. L.; Noguez, C.; Beránek, J.; Barnard, A. S. J. Phys. Chem. C 2014, 118, 9128-9136.

(33) Sauceda, H. E.; Garzón, I. L. J. Phys. Chem. C 2015, 119, 10876-10880.

(34) Bayle, M.; Benzo, P.; Combe, N.; Gatel, C.; Bonafos, C.; Benassayag, G.; Carles, R. Phys. Rev. B 2014, 89, 195402.

(35) Reinhard, D.; Hall, B. D.; Ugarte, D.; Monot, R. Phys. Rev. B 1997, 55, 7868-7881.

(36) Kresse, G.; Furthmüller, J. Computational Materials Science 1996, 6, 15 - 50.

(37) Blöchl, P. E. Phys. Rev. B 1994, 50, 17953-17979.

(38) Perdew, J. P. Phys. Rev. B 1986, 33, 8822-8824. 
(39) Perdew, J. P.; Ruzsinszky, A.; Csonka, G. I.; Vydrov, O. A.; Scuseria, G. E.; Constantin, L. A.; Zhou, X.; Burke, K. Physical Review Letters 2008, 100, 136406.

(40) Grimme, S. J. Comput. Chem. 2006, 27, 1787-1799.

(41) Grimme, S.; Antony, J.; Ehrlich, S.; Krieg, H. The Journal of Chemical Physics 2010, 132, 154104 .

(42) Klime, J.; Michaelides, A. The Journal of Chemical Physics 2012, 137, 120901.

(43) Pluth, J. J.; Smith, J. V.; Faber, J. Journal of Applied Physics 1985, 57, 1045-1049.

(44) O'Keeffe, M.; Hyde, B. G. Acta Crystallographica Section B Structural Crystallography and Crystal Chemistry 1976, 32, 2923-2936.

(45) Paufler, P. Crystal Research and Technology 1983, 18, 1318-1318.

(46) Lee, J.-Y.; Punkkinen, M.; Schönecker, S.; Nabi, Z.; Kádas, K.; Zólyomi, V.; Koo, Y.; Hu, Q.-M.; Ahuja, R.; Johansson, B.; Kollár, J.; Vitos, L.; Kwon, S. Surface Science 2018, 674, 51-68.

(47) Kuk, Y.; Feldman, L. C. Physical Review B 1984, 30, 5811-5816.

(48) Culbertson, R. J.; Feldman, L. C.; Silverman, P. J.; Boehm, H. Physical Review Letters 1981, 47, 657-660.

(49) Hay, H.; Ferlat, G.; Casula, M.; Seitsonen, A. P.; Mauri, F. Physical Review B 2015, 92, 144111.

(50) Tsuneyuki, S.; Tsukada, M.; Aoki, H.; Matsui, Y. Physical Review Letters 1988, 61, 869-872.

(51) Guissani, Y.; Guillot, B. The Journal of Chemical Physics 1996, 104, 7633-7644. 
(52) Ngandjong, A. C.; Mottet, C.; Puibasset, J. The Journal of Physical Chemistry C 2016, 120, 8323-8332.

(53) Ngandjong, A. C.; Mottet, C.; Puibasset, J. The Journal of Physical Chemistry C 2017, 121, 3615-3622.

(54) Halbert, S.; Ispas, S.; Raynaud, C.; Eisenstein, O. New Journal of Chemistry 2018, 42, 1356-1367.

(55) Sangiorgi, R.; Muolo, M. L.; Chatain, D.; Eustathopoulos, N. Journal of the American Ceramic Society 1988, 71, 742-748.

(56) Gadre, K. S.; Alford, T. L. Journal of Applied Physics 2003, 93, 919-923.

(57) Allen, J. P.; Scanlon, D. O.; Watson, G. W. Physical Review B 2011, 84, 115141.

(58) Zhou, J.; Li, Z.-H.; Wang, W.-N.; Fan, K.-N. Chemical Physics Letters 2006, 421, 448-452.

(59) Scherer, J. J.; Paul, J. B.; Collier, C. P.; Saykally, R. J. The Journal of Chemical Physics 1995, 103, 113-120.

(60) Chuang, F.-C.; Hsieh, Y.-Y.; Hsu, C.-C.; Albao, M. A. The Journal of Chemical Physics 2007, 127, 144313.

(61) Li, N.; Ching, W.-Y. Journal of Non-Crystalline Solids 2014, 383, 28-32.

(62) Giacomazzi, L.; Martin-Samos, L.; Boukenter, A.; Ouerdane, Y.; Girard, S.; Richard, N. Physical Review B 2014, 90, 014108.

(63) Devine, R. A. B. Journal of Applied Physics 1984, 56, 563-565.

(64) Bogomolova, L.; Teplyakov, Y.; Deshkovskaya, A.; Caccavale, F. Journal of NonCrystalline Solids 1996, 202, 185-193. 
(65) Garrido Fernandez, B.; López, M.; García, C.; Pérez-Rodríguez, A.; Morante, J. R.; Bonafos, C.; Carrada, M.; Claverie, A. Journal of Applied Physics 2002, 91, 798-807.

(66) Veith, G. M.; Lupini, A. R.; Rashkeev, S.; Pennycook, S. J.; Mullins, D. R.; Schwartz, V.; Bridges, C. A.; Dudney, N. J. Journal of Catalysis 2009, 262, 92-101.

(67) Claverie, A. et al. Defect and Diffusion Forum 2006, 258-260, 531-541.

(68) Schmidt, B.; Grambole, D.; Herrmann, F. Nuclear Instruments and Methods in Physics Research Section B: Beam Interactions with Materials and Atoms 2002, 191, 482-486.

(69) Gierada, M.; Petit, I.; Handzlik, J.; Tielens, F. Phys. Chem. Chem. Phys. 2016, 18, $32962-32972$.

\section{Supporting Information Available}

\section{$\mathrm{SiO}_{2}$ structural characteristics}

The number of defects in all the different $\mathrm{SiO}_{2}$ slabs investigated are given in Tab. 4. These structural defects are defined as: three- and five-fold coordinated $\mathrm{Si}$ atoms $\left(\mathrm{SiO}_{3}\right.$ and $\left.\mathrm{SiO}_{5}\right)$, three-fold coordinated $\mathrm{O}$ atoms $\left(\mathrm{OSi}_{3}\right.$ ), Si-O dangling bonds (non-briding oxigen $\mathrm{NBO}$ ) and tetrahedra connected by an edge (edge-sharing tetrahedra).

The pair correlation functions for $\mathrm{Si}-\mathrm{Si}, \mathrm{Si}-\mathrm{O}$ and $\mathrm{O}-\mathrm{O}$ have been computed by averaging over the three $\mathrm{SiO}_{2}$ slabs used for the different crystalline interfaces (100), (110) and (111) to increase the stastitics (Fig. 7). The dashed and bold lines correspond to the systems before and after the DFT relaxation, respectively. Note that there is a slight displacement of the $\mathrm{Si}-\mathrm{O}$ and $\mathrm{O}-\mathrm{O}$ first peaks towards smaller distances after relaxation. This latter is associated with a shift of the $\widehat{S i O S} i$ angle distributions towards smaller angles (Fig. 7). 
Table 4: Number of defects in the different $\mathrm{SiO}_{2}$ slabs.

\begin{tabular}{|l|l|c|c|c|c|c|}
\hline \hline & & $\mathrm{SiO}_{3}$ & $\mathrm{SiO}_{5}$ & $\mathrm{OSi}_{3}$ & $\mathrm{NBO}$ & Edge-sharing \\
\hline \multirow{3}{*}{100} & Sample 1 & 0 & 0 & 0 & 0 & 1 \\
& Sample 2 & 0 & 0 & 0 & 0 & 0 \\
& Sample 3 & 0 & 0 & 0 & 0 & 1 \\
\hline \multirow{3}{*}{110} & Sample 1 & 0 & 0 & 1 & 1 & 0 \\
& Sample 2 & 0 & 1 & 1 & 0 & 1 \\
& Sample 3 & 0 & 0 & 0 & 0 & 0 \\
\hline \multirow{3}{*}{111} & Sample 1 & 0 & 0 & 0 & 0 & 0 \\
& Sample 2 & 0 & 0 & 1 & 1 & 1 \\
& Sample 3 & 0 & 0 & 0 & 0 & 0 \\
\hline \hline
\end{tabular}
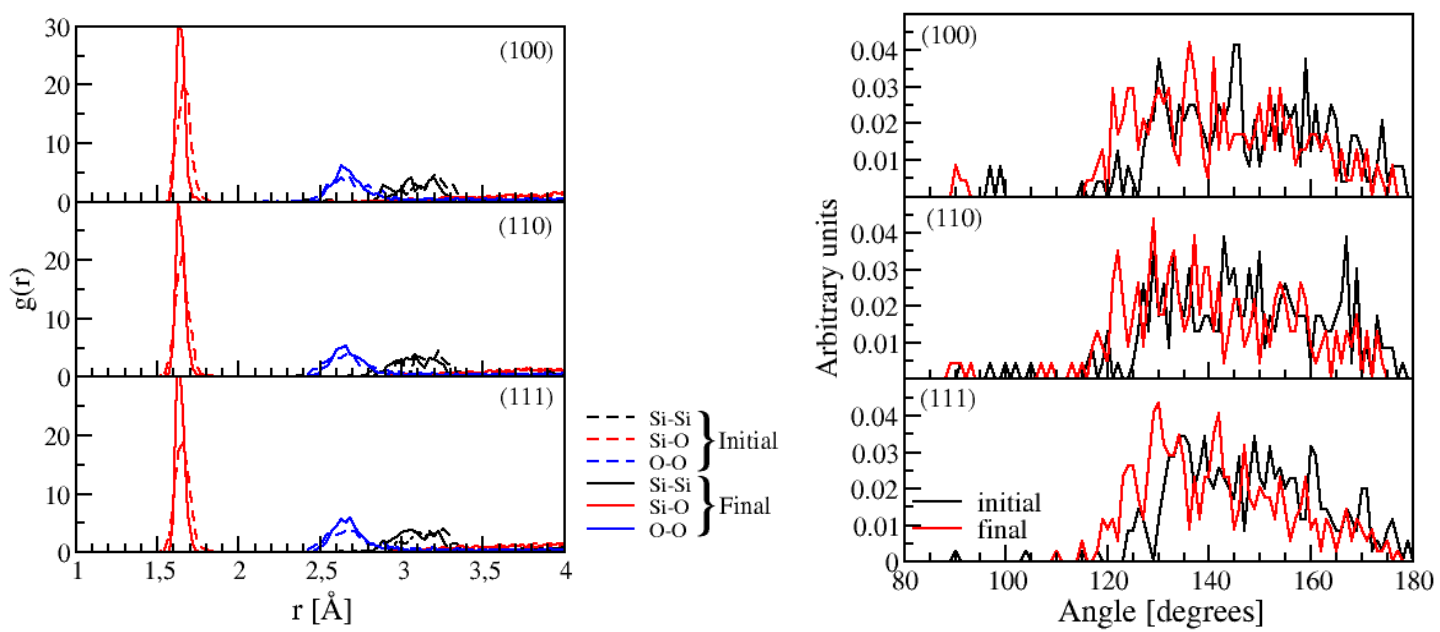

Figure 7: Pair correlation function (left panel) and $\widehat{S i O S} i$ angular distribution function (right panel) of the $\mathrm{SiO}_{2}$ slabs used to model the three crystalline $\mathrm{SiO}_{2} / \mathrm{Ag}$ interfaces (100), (110) and (111). The $g(r)$ and angular distribution are averaged over the three samples for each interface and are compared before and after the DFT relaxation.

The distribution of connected tetrahedra (rings) have been evaluated before and after DFT relaxation and are shown for all $\mathrm{SiO}_{2}$ slabs in Fig. 8. The decrease of the number of rings after relaxation in some of the samples corresponds the breaking of the Si-O bonds.

\section{Interface characteristics}

Tab. 5 presents some structural features of the relaxed samples as well as the work of adhesion of the interface. The slab thickness was determined by the largest z-coordinate 

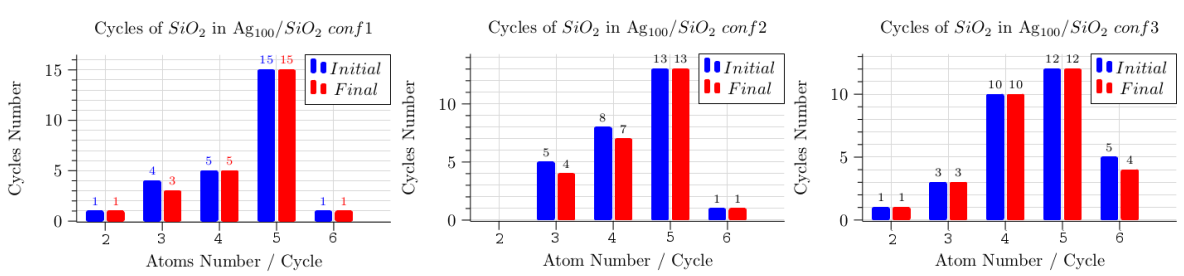

Cycles of $\mathrm{SiO}_{2}$ in $\mathrm{Ag}_{110} / \mathrm{SiO}_{2}$ confl

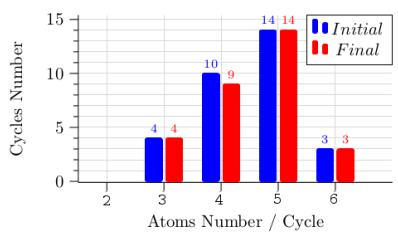

Cycles of $\mathrm{SiO}_{2}$ in $\mathrm{Ag}_{110} / \mathrm{SiO}_{2}$ conf 2

Cycles of $\mathrm{SiO}_{2}$ in $\mathrm{Ag}_{110} / \mathrm{SiO}_{2}$ conf 3
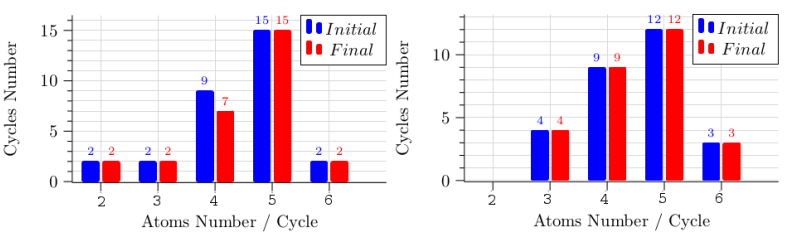

Cycles of $\mathrm{SiO}_{2}$ in $\mathrm{Ag}_{111} / \mathrm{SiO}_{2}$ conf 1

Cycles of $\mathrm{SiO}_{2}$ in $\mathrm{Ag}_{111} / \mathrm{SiO}_{2}$ conf2
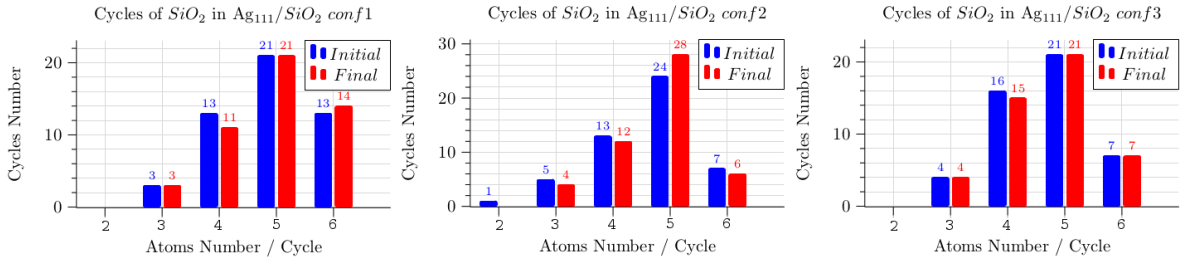

Figure 8: Number of rings of size $N, N$ being the number of terahedra per ring before and after relaxation in all $\mathrm{SiO}_{2}$ slabs.

difference, $\Delta z$, between two atoms belonging to the two different surfaces of a given slab. The work of adhesion $W_{a d}$ is obtained using:

$$
W_{a d}=\left[E\left(\mathrm{SiO}_{2}\right)+E(\mathrm{Ag})-E\left(\mathrm{Ag} / \mathrm{SiO}_{2}\right)\right] / 2 \mathrm{~A}
$$

where $E\left(\mathrm{SiO}_{2}\right)$ is the total energy of the $\mathrm{SiO}_{2}$ slab alone, $E(\mathrm{Ag})$ is the total energy of the $\mathrm{Ag}$ slab alone, $\mathrm{E}\left(\mathrm{Ag} / \mathrm{SiO}_{2}\right)$ is the total energy of the interface system and $A$ is the area of the interface. Note that $\mathrm{W}_{a d}$ is the average value of the works of adhesion of the two interfaces in a given sample. 
Table 5: Cell dimensions, slabs thickness (in $\AA$ ), number of Si-O broken bonds and work of adhesion (in $\mathrm{mJ} . \mathrm{m}^{-2}$ ) after cell and atomic positions relaxations.

\begin{tabular}{|c|c|c|c|c|}
\hline & & $\overline{\mathrm{Ag}(100) / \mathrm{SiO}_{2}}$ & $\mathrm{Ag}(110) / \mathrm{SiO}_{2}$ & $\overline{\mathrm{Ag}}(111) / \mathrm{SiO}_{2}$ \\
\hline \multirow{7}{*}{ Sample 1} & Lx & 12.121 & 12.114 & 14.224 \\
\hline & Ly & 12.121 & 11.421 & 14.782 \\
\hline & $\mathrm{Lz}$ & 25.356 & 24.226 & 24.060 \\
\hline & Ag thickness & 10.534 & 10.423 & 9.971 \\
\hline & $\mathrm{SiO}_{2}$ thickness & 10.968 & 10.084 & 10.823 \\
\hline & broken Si-O bonds & 1 & 1 & 2 \\
\hline & $\mathrm{W}_{a d}$ & 401 & 550 & 505 \\
\hline \multirow{7}{*}{ Sample 2} & $\mathrm{Lx}$ & 12.110 & 12.092 & 14.258 \\
\hline & Ly & 12.110 & 11.400 & 14.818 \\
\hline & $\mathrm{Lz}$ & 25.084 & 24.785 & 24.174 \\
\hline & Ag thickness & 10.675 & 10.441 & 9.848 \\
\hline & $\mathrm{SiO}_{2}$ thickness & 11.289 & 11.073 & 10.562 \\
\hline & broken Si-O bonds & 2 & 0 & 1 \\
\hline & $\mathrm{W}_{a d}$ & 579 & 326 & 468 \\
\hline \multirow{7}{*}{ Sample 3} & Lx & 12.151 & 12.096 & 14.218 \\
\hline & Ly & 12.151 & 11.404 & 14.776 \\
\hline & $\mathrm{Lz}$ & 25.326 & 25.212 & 24.785 \\
\hline & Ag thickness & 10.423 & 10.542 & 9.754 \\
\hline & $\mathrm{SiO}_{2}$ thickness & 11.059 & 10.558 & 10.970 \\
\hline & broken Si-O bonds & 1 & 0 & 1 \\
\hline & $\mathrm{W}_{a d}$ & 464 & 292 & 477 \\
\hline
\end{tabular}




\section{Graphical TOC Entry}

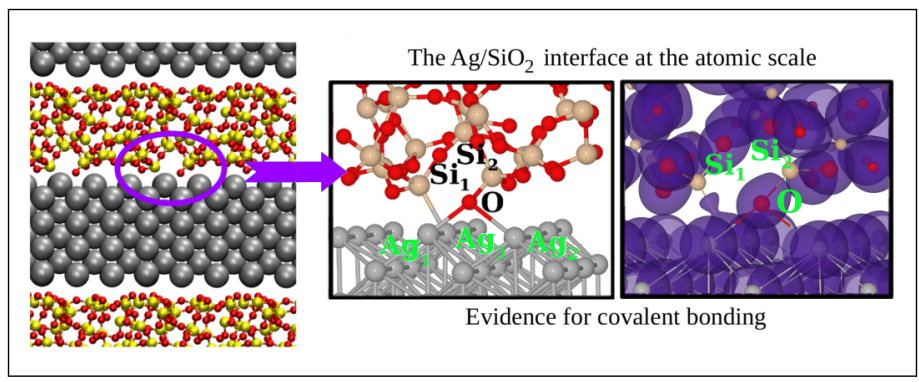

